\title{
Research Paper \\ Effect of Psychodrama on Post-traumatic Stress Disorder Symptoms in Primary School Students Living in Earthquake-stricken Areas
}

\author{
*Farideh Hamidi ${ }^{1}$ (1) Shoaib Sobhani Tabar ${ }^{1}$ (1)
}

1. Department of Educational Sciences, School of Humanities, Shahid Rajaee Teacher Training University, Tehran, Iran

\begin{tabular}{|l|l|l|}
\hline $\begin{array}{l}\text { Use your device to scan } \\
\text { and read the article online }\end{array}$ & $\begin{array}{l}\text { Citation Hamidi F, Sobhani Tabar Sh. [Effect of Psychodrama on Post-traumatic Stress Disorder Symptoms in Primary School } \\
\text { Students Living in Earthquake-stricken Areas (Persian)]. Iranian Journal of Psychiatry and Clinical Psychology. 2021; 26(4):400- } \\
\text { 417. http://dx.doi.org/10.32598/ijpcp.26.4.3190.2 }\end{array}$ \\
doi http://dx.doi.org/10.32598/ijpcp.26.4.3190.2
\end{tabular}

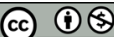

Received: 19 Sep 2019

Accepted: 08 Jun 2020

Available Online: 01 Jan 2021

Key words:

Psychodrama, Post-

Traumatic Stress

Disorder, PTSD

\section{A B S T R A C T}

Objectives This study aims to determine the effectiveness of psychodrama in reducing the symptoms of Post-Traumatic Stress Disorder (PTSD) in primary school students living in earthquake-stricken areas. Methods This is a quasi-experimental study with pre-test/post-test design using a control group. The study population consists of all male primary school students diagnosed with PTSD living in Salas-e Babajani County, Kermanshah, Iran. Of these, 40 were selected using a purposive sampling method and based on the PTSD criteria, and were then divided into two groups of intervention $(n=20)$ and control $(n=20)$. Research instruments were a diagnostic interview based on Diagnostic and Statistical Manual of Mental Disorders, $5^{\text {th }}$ Edition (DSM-5) criteria and the PTSD Checklist for DSM5 (PCL-5) questionnaire. Data were analyzed using one-way and multivariate analysis of covariance.

Results Psychodrama reduced the symptoms of PTSD in children with an effect size of $0.51(P<0.001)$. Conclusion Psychodrama is an effective method for reducing the PTSD symptoms and neuropsychological problems. For the generalization of its results, further studies are recommended.

\section{Extended Abstract}

\section{Introduction}

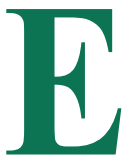

arthquakes, as a natural disaster, are very destructive with wide range of effects and pose serious threat to the safety of human life [2]. Millions of children across the world face traumatic events, including natural disasters.

Some of these children develop a clinical syndrome called Post-Traumatic Stress Disorder (PTSD). This disorder refers to a set of behavioral, cognitive, and emotional symptoms resulted from repeated or severe exposure to one or more traumatic events, lasting for more than one month, and is associated with many symptoms such as frequent recall of traumatic events, avoidant behaviors, sleep disorders and nightmares, and concentration problems, and is not caused by substance abuse or physical diseases. This disorder cannot be explained by other disorders [3]. PTSD is classified in the section related to trauma and stress. It is known as a trauma-related disorder, where one has exaggerated negative beliefs causing stress [4]. Children with PTSD are highly sensitive to environmental hazards, and sleep disorders are very common in them such as difficulty falling asleep or mid-sleep awakenings. They become more irritable than before and report problems in concentration, especially on their homework. In addition, they experience cognitive changes in the form of negative automatic thoughts where they feel that the world is a very dangerous place or that their lives will be very unstable and fragile [16].

* Corresponding Author:

Farideh Hamidi, PhD.

Address: Department of Educational Sciences, School of Humanities, Shahid Rajaee Teacher Training University, Tehran, Iran.

Tel: +98 (21) 22970035

E-mail: fhamidi@sru.ac.ir 
In general, according to studies on earthquake victims, there is a high likelihood of PTSD development in them, especially in children, which can cause many psychological, communication and emotional problems and poor academic performance. Therefore, community-based interventions are essential for affected children. One of the most effective therapies whose effect on many psychological variables has been studied is psychodrama therapy whose concepts were introduced by Moreno. Psychodrama has been used as an effective method in many educational, cultural, psychiatric and rehabilitation centers, and as its name implies, it refers to a treatment in which the therapist tries to rehabilitate people in need with the help of various theatrical techniques [22]. Psychodrama was originated from the discovery that representing own conflicts enable people to release repressed feelings [25].

Since school students are intellectual and spiritual assets of each country, ensuring their physical and mental health should be one of the most important goals of decision makers. On the other hand, earthquakes are unpredictable natural disasters and their destructive financial and psychological negative effects have made them one of the most dangerous natural disasters in the world. Given that Iran is situated in an area prone to earthquakes, there is a need for taking measures to protect survivors, especially children in this country. According to studies, the most common complication of natural disasters is PTSD development in children. In this regard, necessary measures and identification of their specific psychological and rehabilitation needs in the early stages are of particular importance in helping them and preventing long-term secondary injuries and consequences in them. Therefore, given that the importance and effectiveness of psychodrama therapy on some disorders has already been proven, and due to the lack of coherent and sufficient related studies, the present study aims to evaluate the effectiveness of psychodrama therapy in reducing the PTSD of elementary school students in an earthquake-stricken area of Iran.

\section{Methods}

This is a quasi-experimental study with pre-test and post-test design using control group. The study population consists of all male students with PTSD aged 9-12 years who were studying in elementary schools $\left(4^{\text {th }}-6^{\text {th }}\right.$ grade $)$ in Salas-e Babajani County, Kermanshah, Iran in 2017. First, four schools were selected randomly and then 40 samples with PTSD were recruited from these schools purposefully according to a diagnostic interview based on the Diagnostic and Statistical Manual of Mental Disorders, 5th Edition (DSM-5) criteria and completing the PTSD Checklist for DSM5 (PCL-5) questionnaire. They were randomly divided into two groups of intervention $(n=20)$ and control $(n=20)$. Then, the intervention group received psychodrama therapy at 1390 -min sessions, while the control group received no any treatment. After the intervention, both groups were re-evaluated with the help of their teacher. Finally, the data were collected and analyzed in SPSS V. 22 software using descriptive statistics (mean, standard deviation) and inferential tests including one-way and Multivariate Analysis of Covariance (MANCOVA)

\section{Results}

The mean total pre-test and post-test scores of PTSD in the intervention group were 46.65 and 37.50 and in the control group were 48.50 and 47.10, respectively. MANCOVA was performed to examine the effect of psychodrama therapy on the post-test PTSD scores of the study groups by controlling the pre-test score. The results showed a significant difference between the two study groups in the post-test PTSD ( $\mathrm{F}=9.877, \mathrm{P}<0.001)$ (Table 1). To examine this effect more accurately, one-way analysis of covariance was performed. To understand this difference, the mean post-test PTSD scores of the intervention and control groups were compared. The results showed that the difference was significant in terms of PTSD $(\mathrm{F}=38.360, \mathrm{P}<0.000)$. As a result, the research hypothesis was confirmed.

\section{Discussion}

The results showed that the PTSD symptoms were reduced after psychodrama therapy, while there was no considerable change in the control group. According to MANCOVA results, the difference between the intervention and control groups in the PTSD score was statistically significant. These findings are somehow consistent with other studies conducted by Afarini and Hosseini (2018) [32], Cheraghi (2017) [50], Pourrezaian (2016) [34], Sepanta, Qamarani

Table 1. The results of one-way analysis of covariance in post-test comparison

\begin{tabular}{ccccccc}
\hline Dependent Variable & Total Squares & df & Average Squares & F & Sig. & Effect size \\
\hline Symptoms of post-traumatic stress & 592.363 & 1 & 592.363 & 38.360 & 0.0001 & 0.512 \\
\hline
\end{tabular}


and Hashemi (2015) [52], Terzigloo and Ozkan (2018) [53], Trashova et al. (2017) [40]. These studies showed the positive effects of psychodrama on various variables such as anxiety, fear, and depression. In psychodrama, a person reconsiders his/her problem by discovering and displaying the psychological aspects of that problem. Psychodrama techniques create a better understanding of reality and reduce anxiety and stress by creating appropriate situations and mental space, sharing emotions, and expressing them. During psychodrama, children re-enact their past traumatic experiences in their role-plays in order to gain a better understanding of them and to be able to have more control on them over time. From this perspective, psychodrama can have general consequences such as reduced depression or specific outcomes such as behavior change and improved relations and self-esteem. In a safe environment, people can easily take risks and thus observe and evaluate their actions. Psychodrama is a kind of emotional release that deals with solving problems and presenting aspects of life, in addition to showing the audience the role of the individual in interpersonal relations. In psychodrama, the past fears and future hopes are transferred to the present time and solved.

In general, it can be concluded that psychodrama is effective in reducing PTSD symptoms and improving neuropsychological functions in male children living in earthquakeprone areas. This method can be used as an adjunctive treatment for PTSD along with other methods such as medication. The results of this study can be useful for psychologists, theater/drama teachers, school teachers, counselors, educational planners, children with cognitive impairments, and children affected by earthquake.

\section{Ethical Considerations}

\section{Compliance with ethical guidelines}

All ethical principles are considered in this article. The participants were informed of the purpose of the research and its implementation stages. They were also assured about the confidentiality of their information and were free to leave the study whenever they wished, and if desired, the research results would be available to them (Code: 45312).

\section{Funding}

This research did not receive any specific grant from funding agencies in the public, commercial, or not-forprofit sectors.

\section{Authors contributions}

Conceptualization, methodology, writing, editing \& review: All authors; Interventions: Shoaib Sobhani Tabar; Project administration: Farideh Hamidi.

\section{Conflicts of interest}

The authors declare no conflict of interest.

\section{Acknowledgements}

The authors would like to thank the Education Department of Salas-e Babajani County in Kermanshah, Iran. 


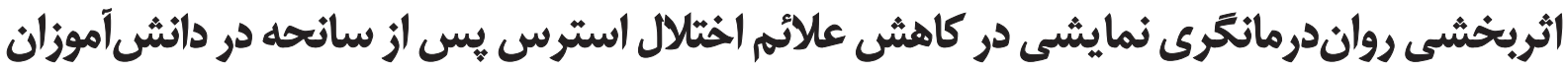

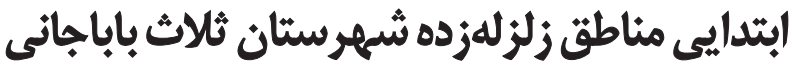

\author{
'فريده حميدى' هـ شعيب سبحانىتبار' (1)
}

ا. كروه علوم تربيتى، دانشكده علوم انسانى، دانشعاه تربيث دبير شهيد رجايى، تهران، ايران.

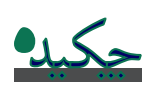

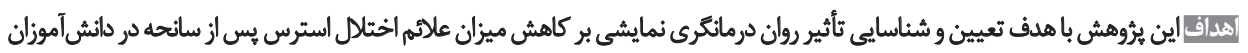

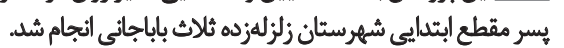

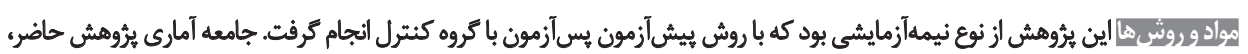

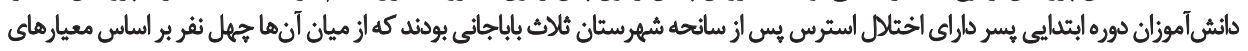

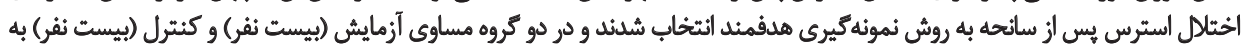

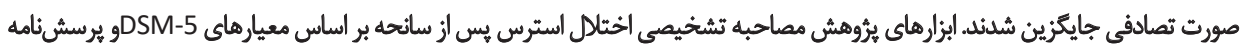

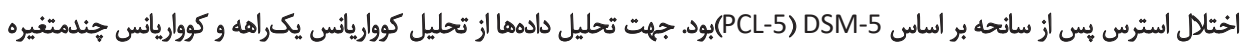

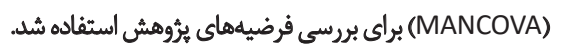

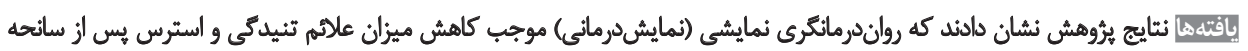

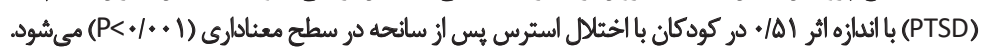

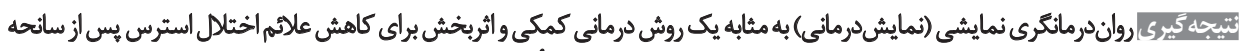

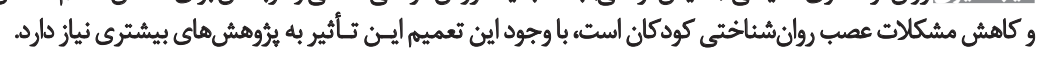

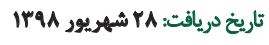
تاريخ بذيرش: 19 أخرث|د

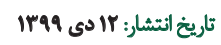

كليدوازٔهها:

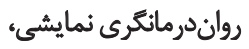

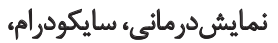

اختلال استرس يس ازئ سانحه اختل الحن.

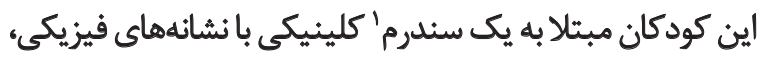

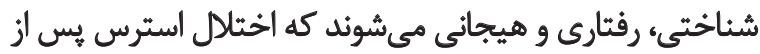

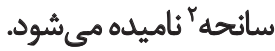
اين مفهوم عبارت است از مجموعهاى از نشانههاى رفتارى،

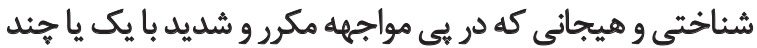

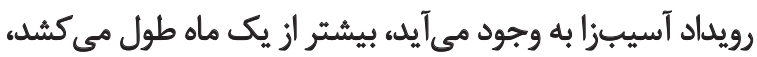

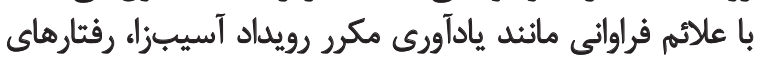

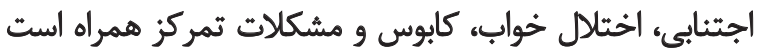

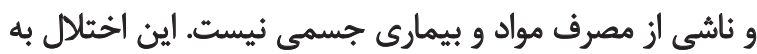

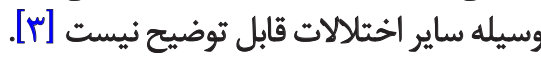

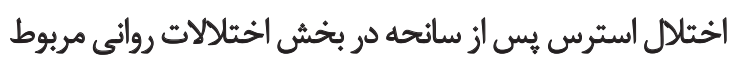

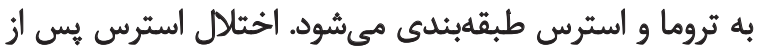

1. Syndrome

2. Post-traumatic Stress Disorder

Aates

هر ساله كشور ما در معرض بلاياى طبيعى، از انواع كوناكون

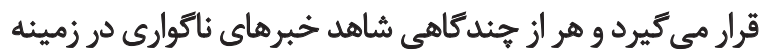
وقوع يكى از آنها در نقاطى از كشور هستيمه

بنا بر كزارش دفتر امور هماهنگكنئده كمكهاي انسان

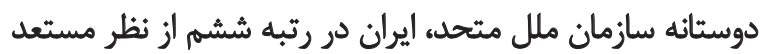

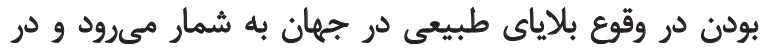

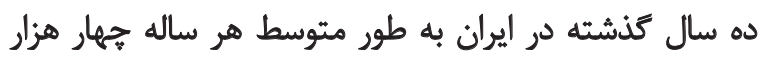

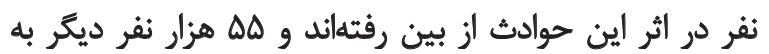

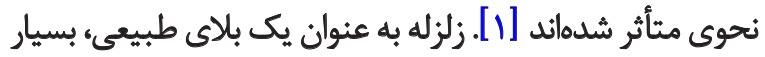

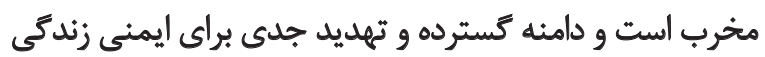

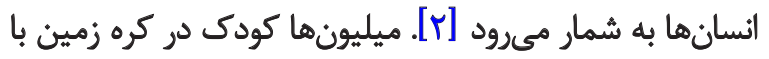

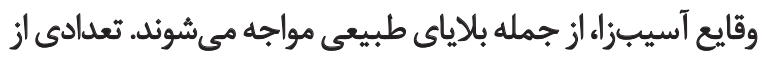

두.

: نويسئده مسئول:

دكتر فريده

نشاثي: تهران، دانشكاه تربيت دبير شهيد رجائي، دانشكده علوم انسائى، كروه علوم تربيتى.

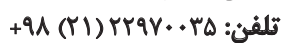

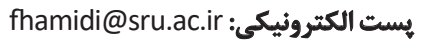




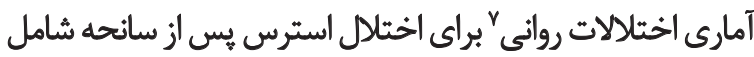

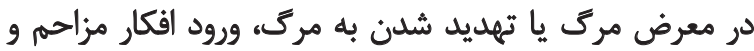

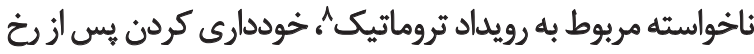

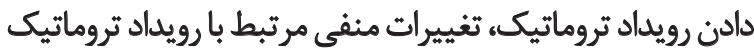

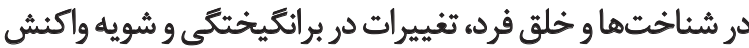

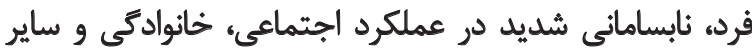
جنبهاى مهم زندكى است

در ملاكهاى تشخيصى DSM-5 در مورد اختلال استرس

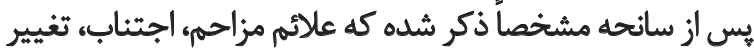

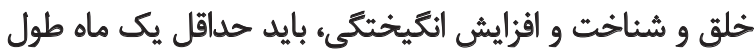

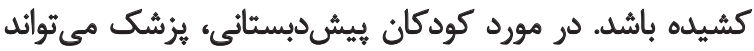

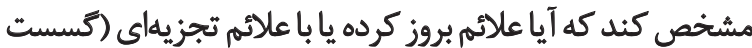

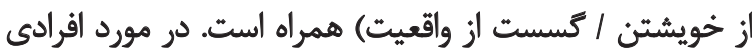

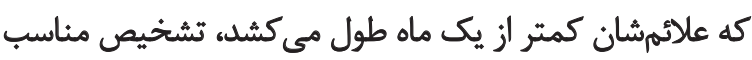

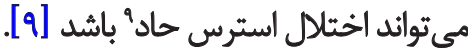
در DSMM-5 مقايسه با نسخه قبلى، ملاكهاى روشنترى

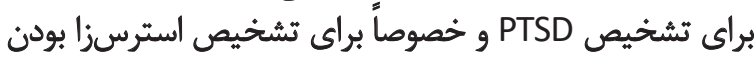

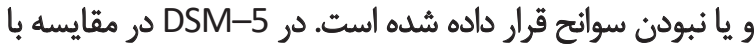

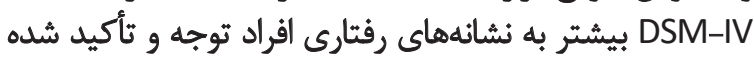

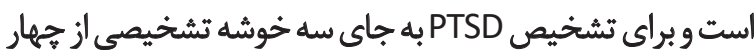

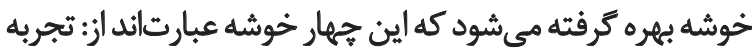

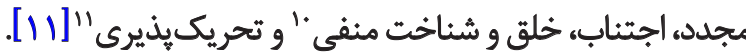
ريجارد بريانت و همكاران، در بررسى ثأثير اختلال استرس

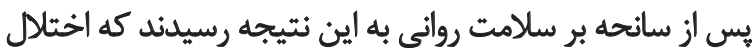

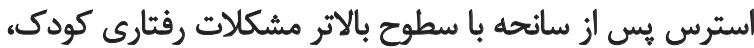

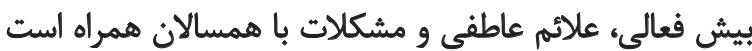

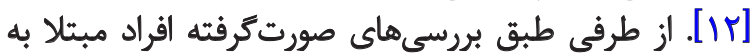
تا تانقص در كاركردهاى شناختى، از جمله عملكرد حافظه،

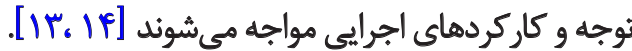

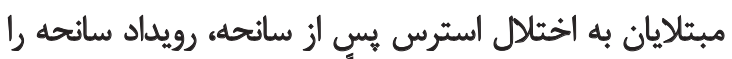

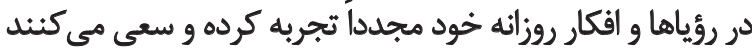

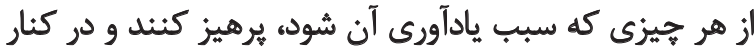

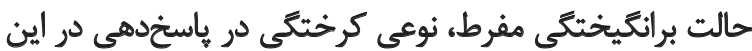

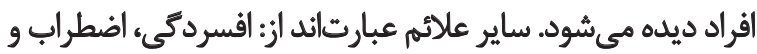

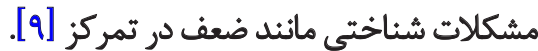

از جمله نشائهاى اختّلال استرس بـ إس از سانحه ميثتوان

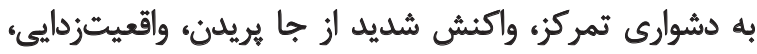

7. Diagnostic and Statistical Manual of Mental Disorders ( $5^{\text {th }} \mathrm{Ed}$ )

8. Traumatic

9. Acute Stress Disorder

10. Negative Mood and Cognition

11. Arousal
سانحه به عنوان يك اختلال مرتبط با آسيب شناخته ميشودود

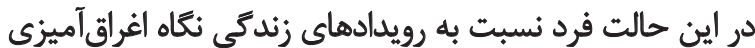

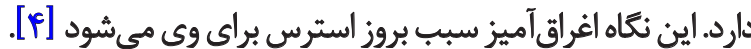
حوادثى از قبيل جنَّ، زلزله، سيل، تصادف، سوءاستفاده

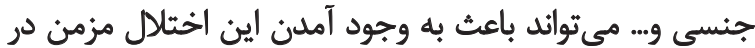

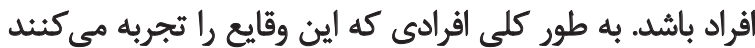

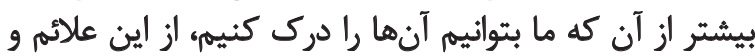

$$
\text { تنيدكى ها رنج مىبرئد. }
$$

مطالعات بسيارى نشان دادهاند كه به از مواجهه باز لزاله، ميزان

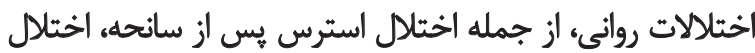

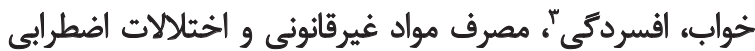

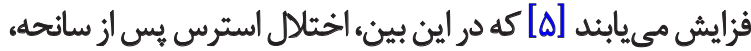

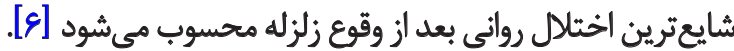
اختلال استرس يّ از سانحه، يك اختلال ناشى از حوادثى إنى إنى

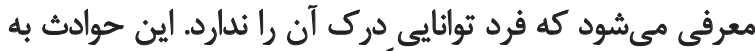

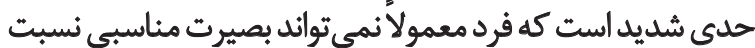

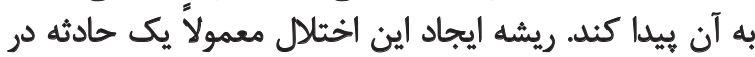

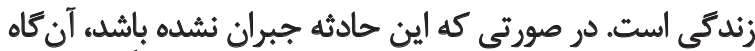

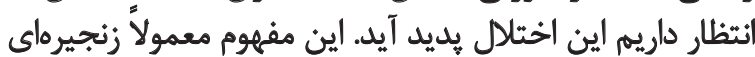

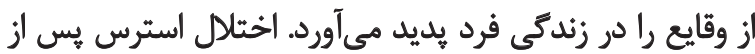

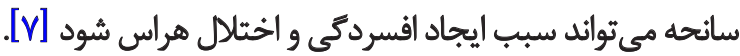
يانگ و همكاران ادعا دارند كه تحقيقات علم روانشناسى رودي

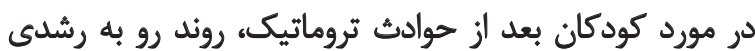

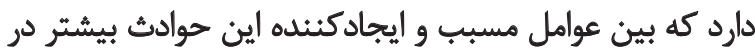

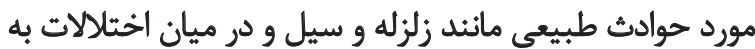

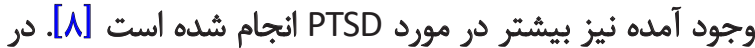

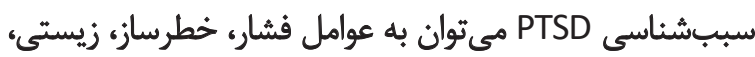
روانيريشى و شناختى رفتارى اشاره كرد [9]. نظريههاى متعددى در خصوص تبيين اختلال استرس يّ

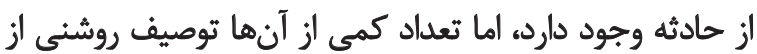

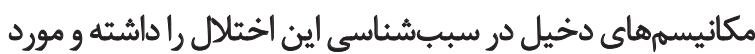

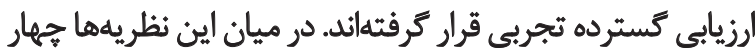

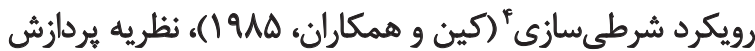

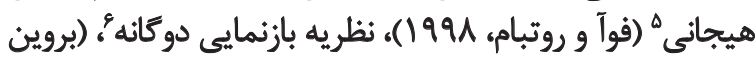

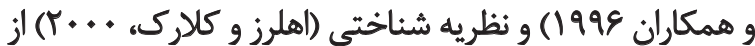

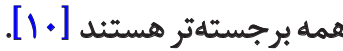

از جمله عوامل معيارهاى ينجمين نسخه راهنماى تشخيصى و

3. Depression

4. Conditioning Theory

5. Emotional Processing Model

6. Dual Representation Model 
طبيعى و انسانى مواجه است. در بيدايش بلاياى طبيعى برخلاف

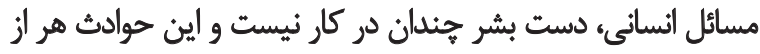

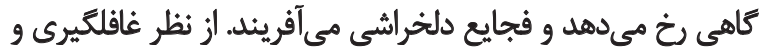

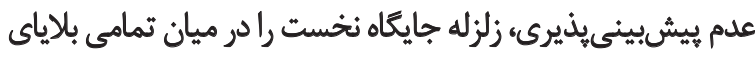
طبيعى به خود اختصاص داده است.

كشور ايران به دليل قرار كرفتن روى كمربئد زلزله يكئ يكى از

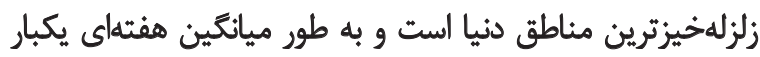

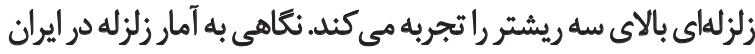

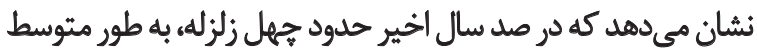

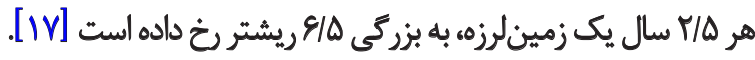

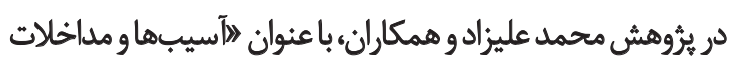

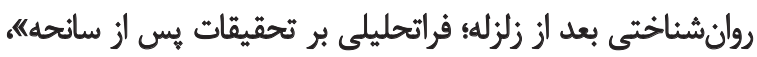

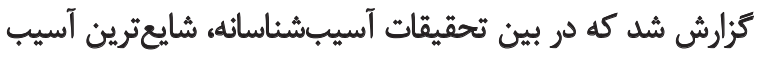

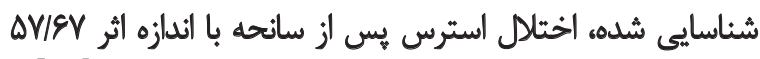

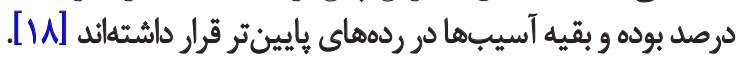

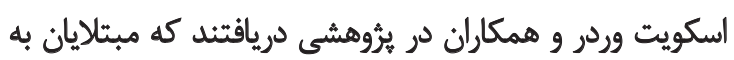

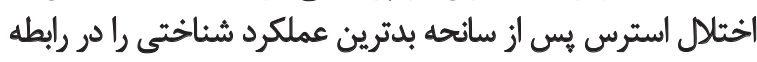

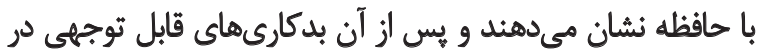

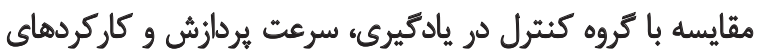

اجرايى نشان دادند [19].

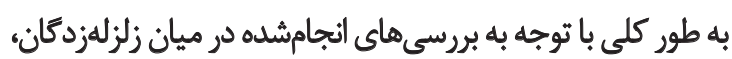

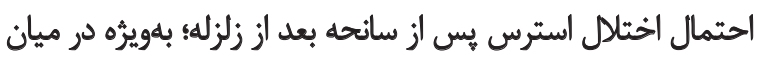

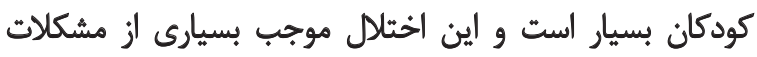

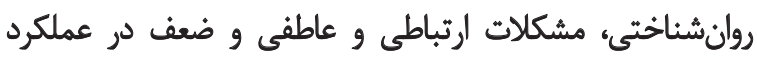

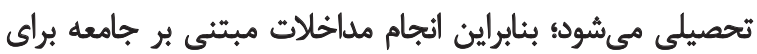
كودكان آسيبديده ضرورى است.

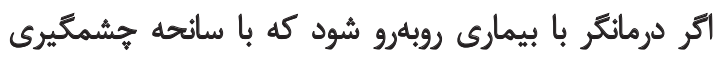

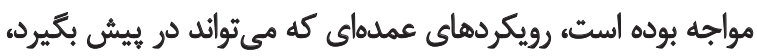

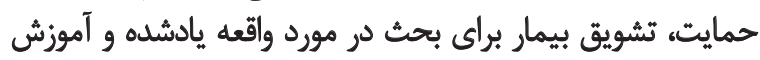

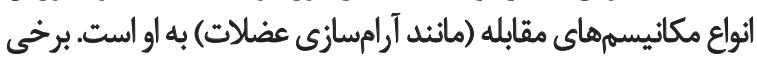

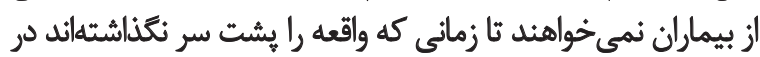

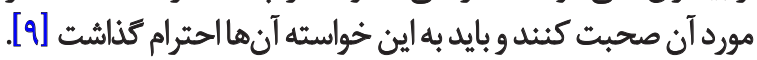

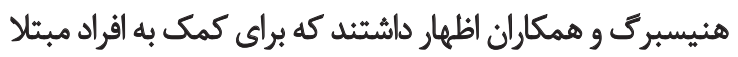

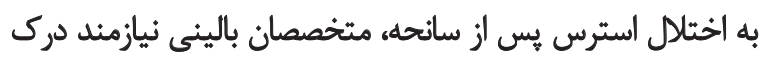

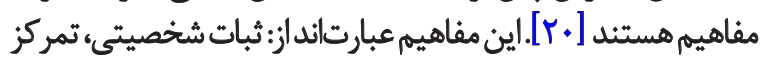

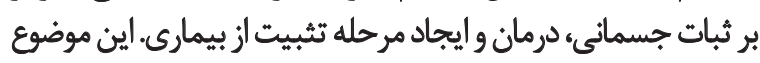

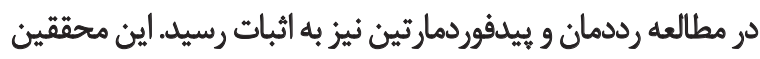

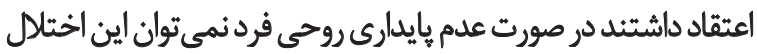

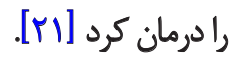

شخصيت باختكى، كاهش آكاهي از محيط، ناتوانى در به

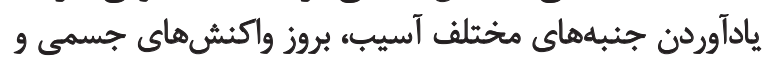

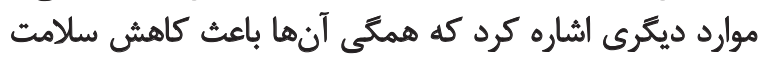

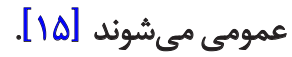

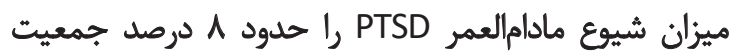

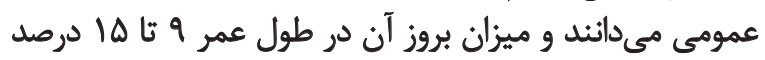

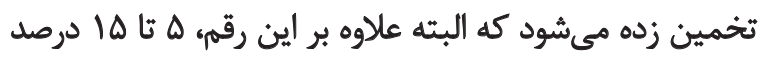

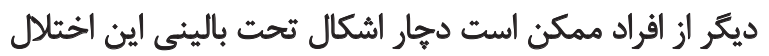

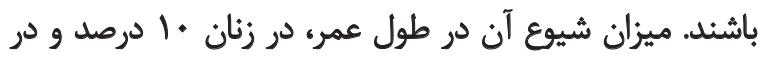

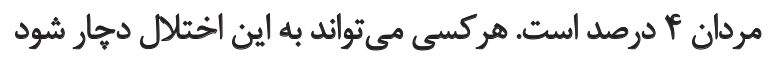
و هيجكسى از اين لحاظ مصونيت ندارد.

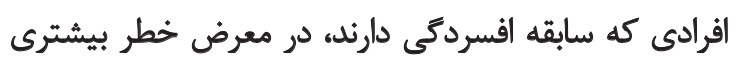

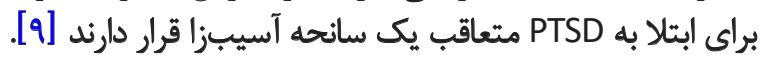

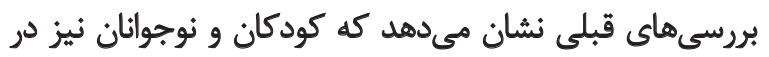

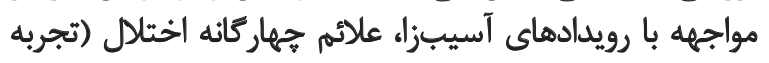

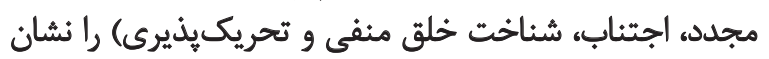

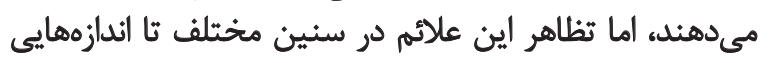

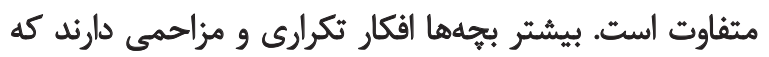

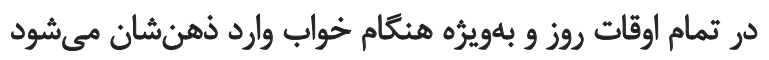

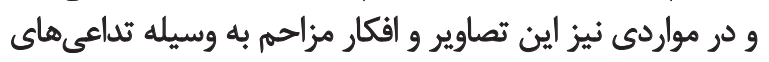
محيطى راهاندازى مي نيوند.

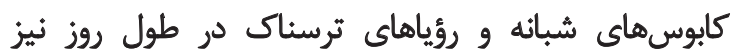

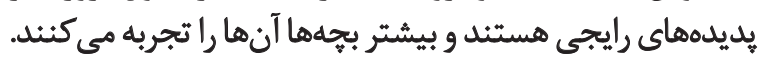

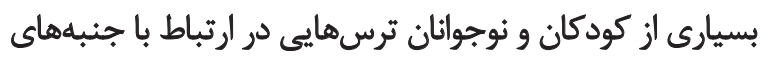

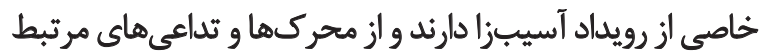

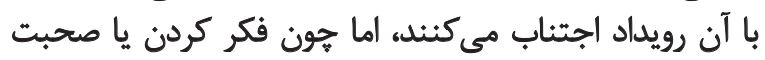

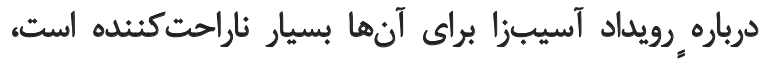
معمولاً از اين كار اجتناب مى كنيند.

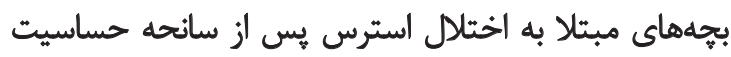

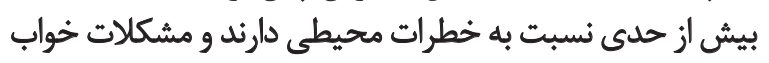

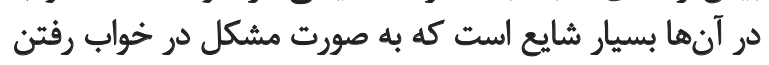

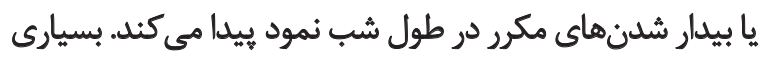

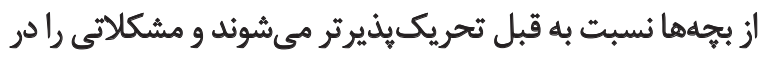

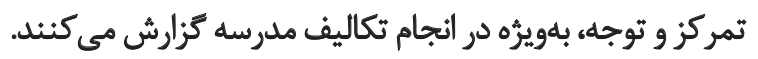
علاوه بر اين، كودكان و نوجوانان تغييرات شناختي نيز تجربه

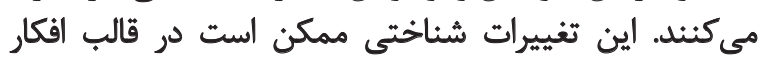
خودآيند منفى با باشد كه در آن بحهنها

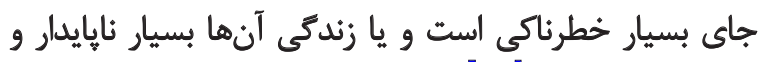
شكنيده خواهد بود [1 19]. زندكى بشر همواره با دو كونه مسئله عام بيشبيني يذير

12. Negative Automatic Thought 
روانيزشك رومانيايي (جاكوب ال مورنو) برمى گردد. مورنو از سال

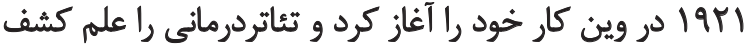

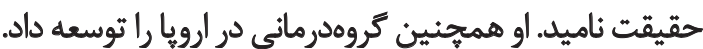
رواننمايشكرى يك روش كروهدرمانى است كه در آن بردي

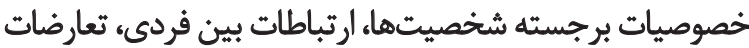

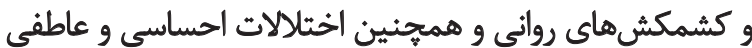

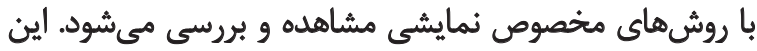

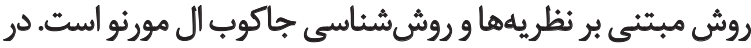

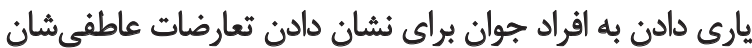

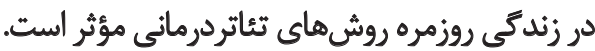
اين روشها در مكانهاى مختلف مائند خانه، درمانكاه مشاوره

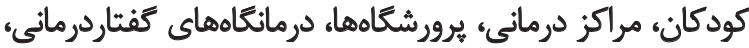

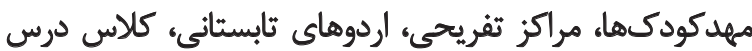

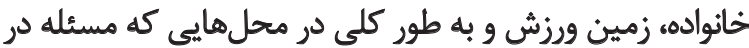

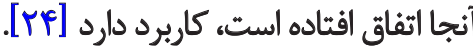

نمايشدرمانى به مثابه يك روش اثربخش در بسيارى از

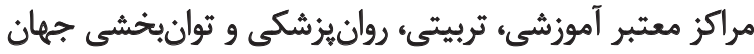

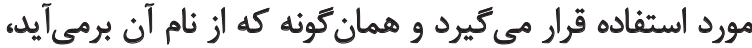

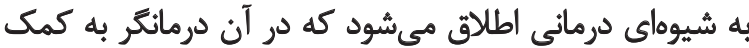

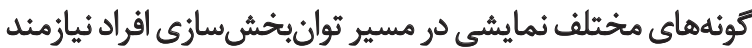

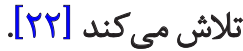
رواندرمانكَرى نمايشى به عنوان نتيجه اكتشافات خود در

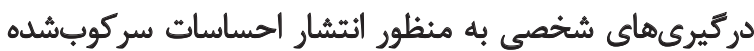

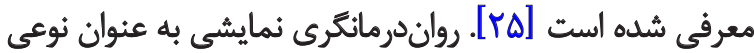

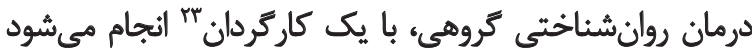

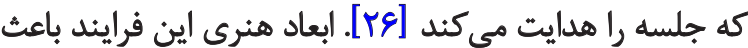

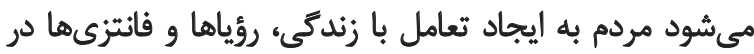

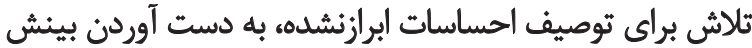

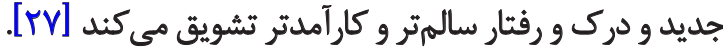

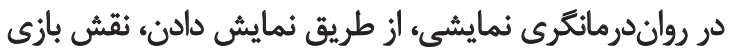

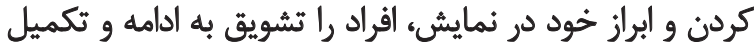

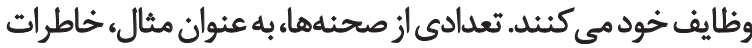

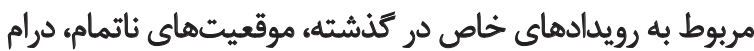

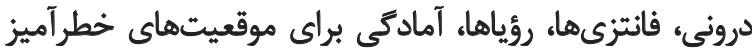

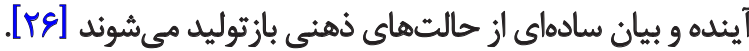
هر دو ارتباط كلامى و غير كلامى در اين فعاليتها مورد استفاده

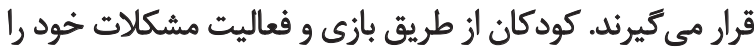

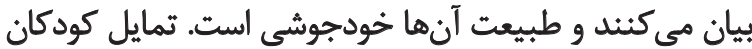

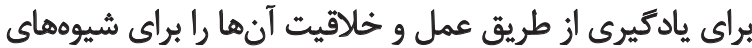

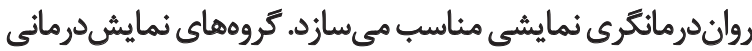

روش هاى درمانى رايجى براى اختّلال استرس يس از سانحه، ازئي

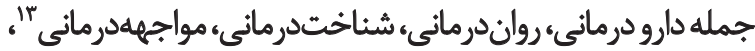

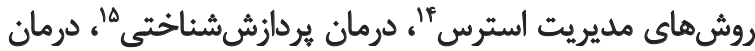

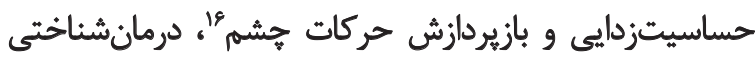

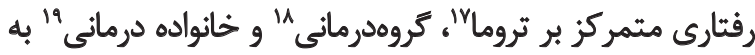

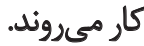

هنرها با روان انسان و خواستههاى اجتماعى اين موجود دو

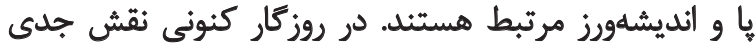

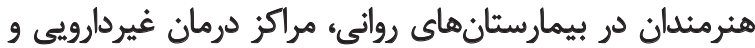

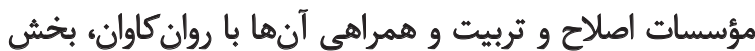

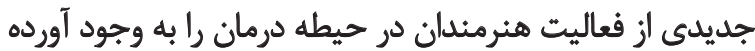
كه تحت عنوان " هنردرمانى " به شهرت رسيد ديده درمان است امروزه هنردرمانى به عنوان مقولهاي تعريفشده در توانبخشى

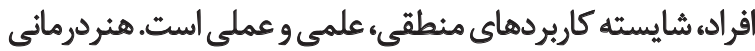

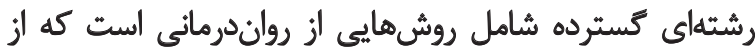

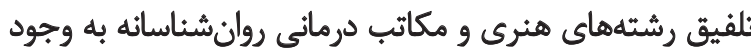

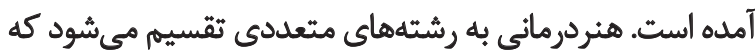

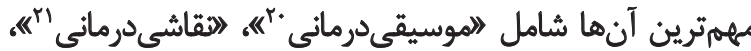

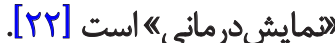

يكى از درمانهاى مؤثر كه اثربخشى آن بر بسيارى از

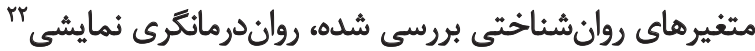

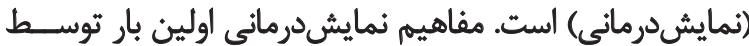
مورنو نشان داده شد. در كُّشته يونانيان، مصريان و روميان باستان، روشهاى

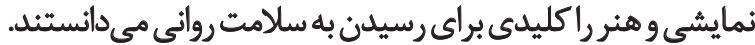

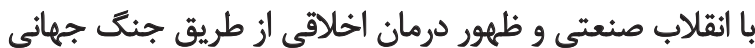

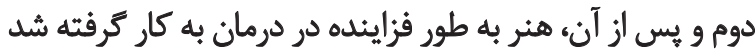

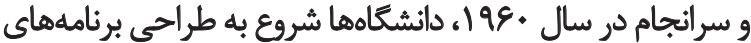

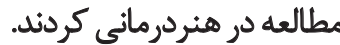

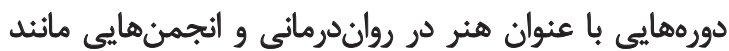

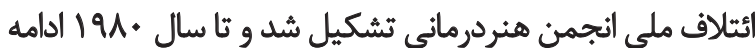

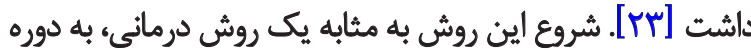

13. Exposure Therapy

14. Stress Management

15. Cognitive Processing Therapy

16. Eye Movement Desensitization and Reprocessing

17. Trauma-Focused Cognitive-Behavioral Therapy

18. Group Therapy

19. Family Therapy

20. Music Therapy

21. Painting Therapy

22. Psychodrama 
إمونا يُنج هدف كلى را براى نمايشدرمانى عنوان مي كند: ابتدا، لاتجلى و كف نفس هيجانات " بدينمعنا كه فرد ياد بكيرد

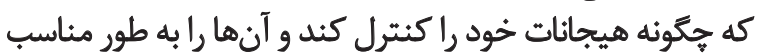

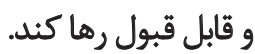

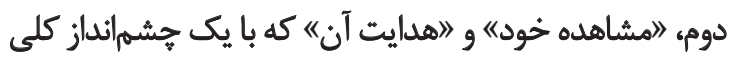

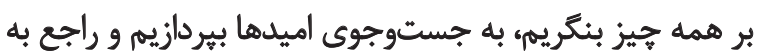
اختيارهاو انتخابها تفكر كنيم.

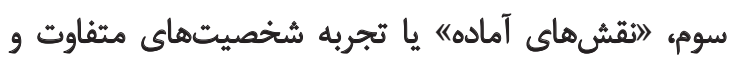

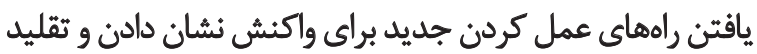

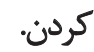

جهارم، ا"تعديل و توسعه تصور از خوده يا تعويض نقشهاى

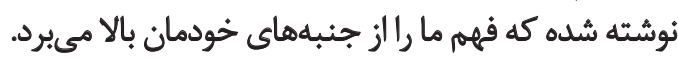

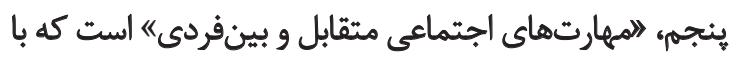

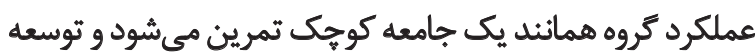
بيدا مي كند [بrir]

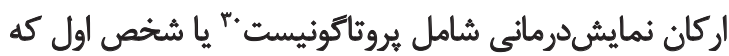

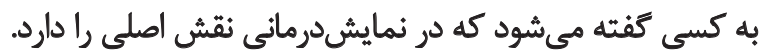

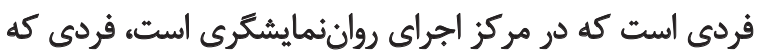

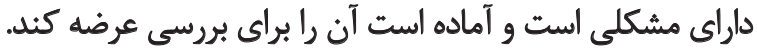

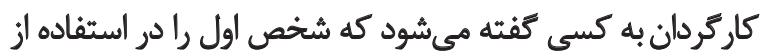

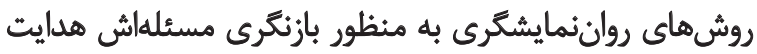

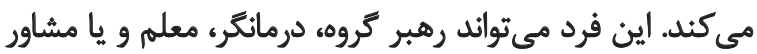

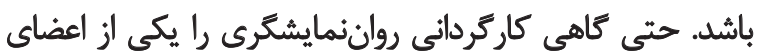
كروه بر عهله مي كيرد كاهي كاركردان.

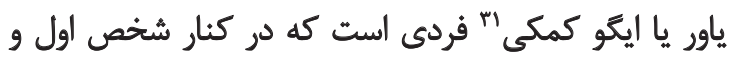

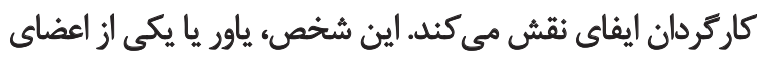

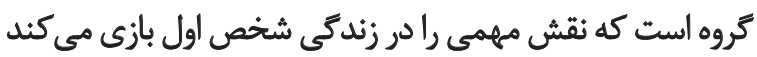

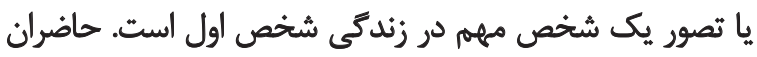

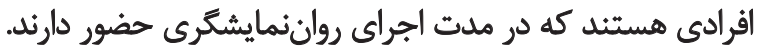

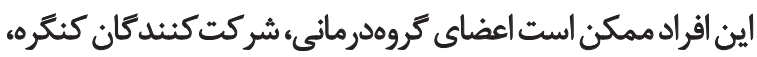

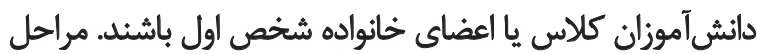

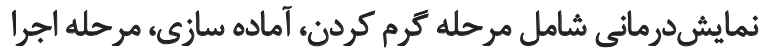

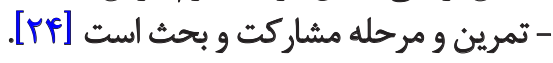
در ايران و خارج از ايران مطالعات متعددى در مورد اثربخشى أرئي

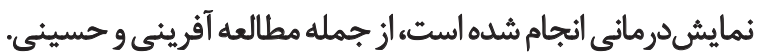

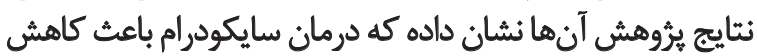

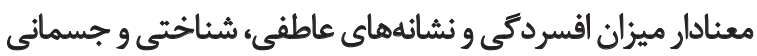

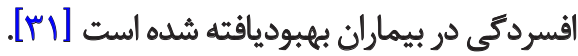

30. Protagonist

31. Auxiliary Ego
اجازه مي دهند كه كودك التوهاي هختلف رفتارى را مشاهده كند

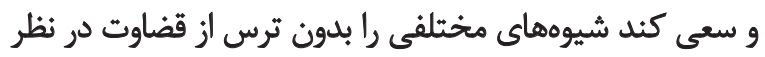

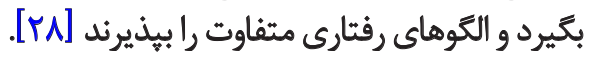

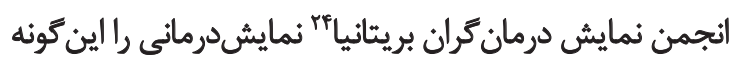

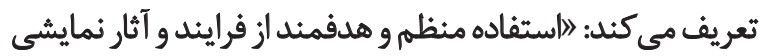

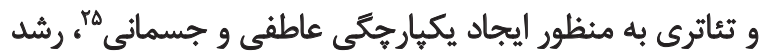

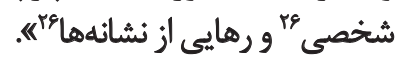

نمايش درماني يك شيوه فُعال و تجربه كُاست. از سويى مي توان

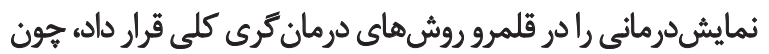

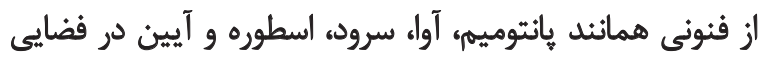

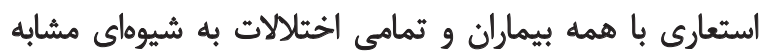

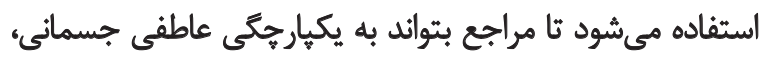

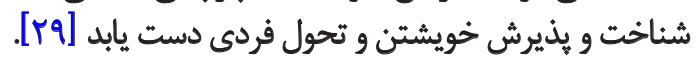

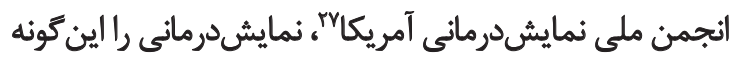

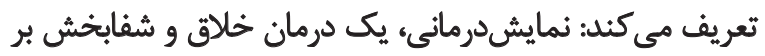

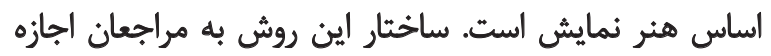

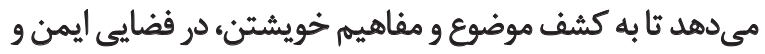

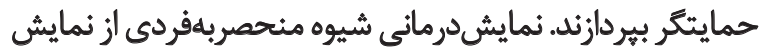

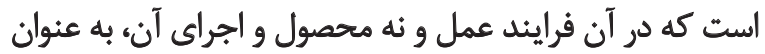

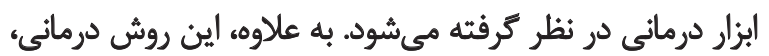

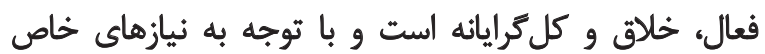
مراجعان، شيوههاي كوناكوني دارد [ـ [ب] رويكردهاى مختلفى ضميمه كار نمايشردمانى قرار

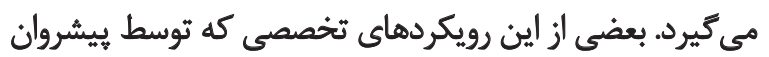

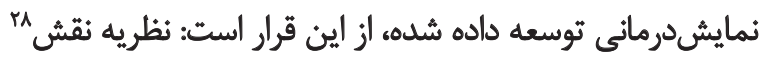

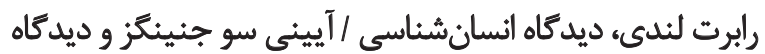
ينتجر حلهاي امونا.

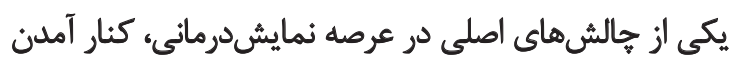

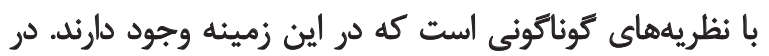

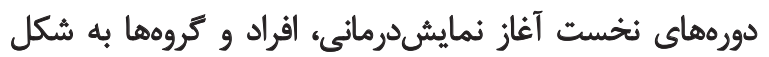

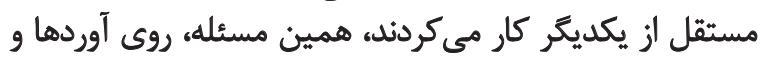

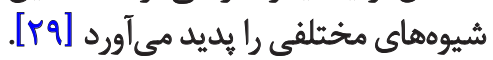

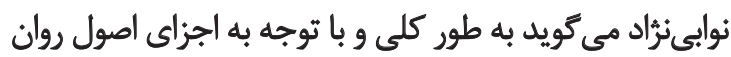

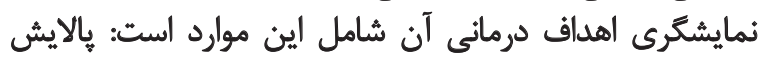

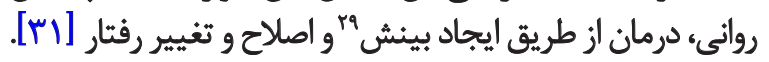

24. The British Association of Dramatherapists

25. Emotional \& Physical Integration

26. Personal Growth

27. National Association of Drama Therapy-USA

28. Role Theory

29. Insight Therapy 
جسمى و روانى آنها بايد از مهمثرين اهداف برنامهريزان آن زئن

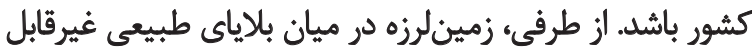

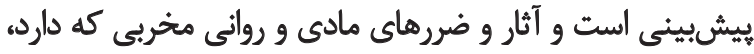
آن رابه مخاطرهبارترين بلاياى طبيعى در جهان تبديل مرئ كرده است.

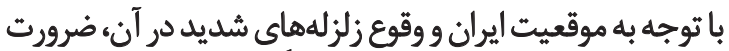

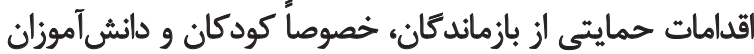

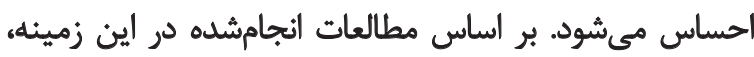

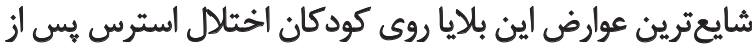

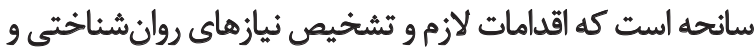

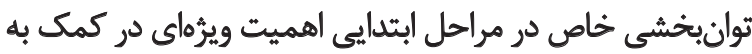

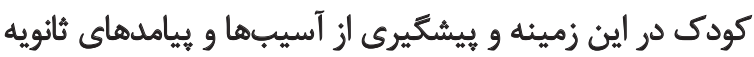

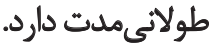

با توجه به اينكه اهميت واثربخش بودن رواندرمانكرى نمايشى إنى

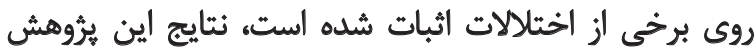

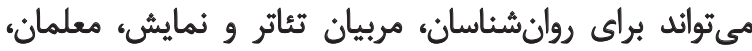

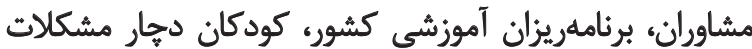

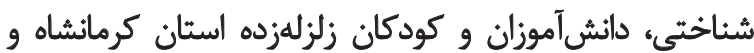
منطقه ثلاث باباجاني مفيد و كار كشا باشدان

بنابراين در يُوهشهاى قبلى مشابه، اثربخشى نمايشدرمانى

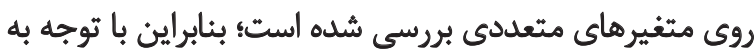

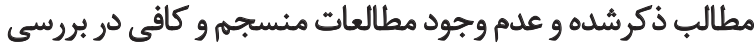

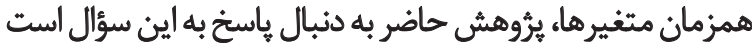

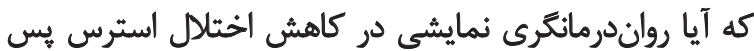

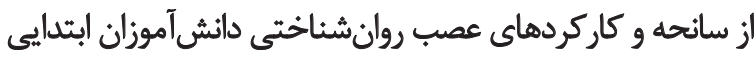
مناطق زلز لهزده شهرستان ثلاث باباجاني مؤثر است؟ راني

تحقيق حاضر از نوع شبهآزمايشى بيشآزمون و ويس آزمون

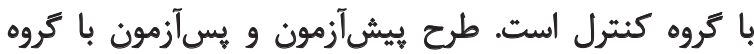

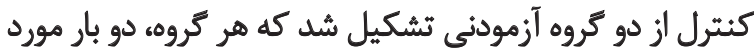

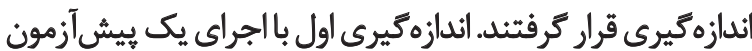

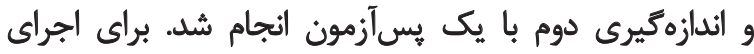

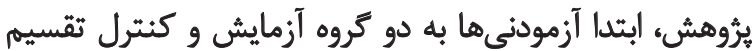

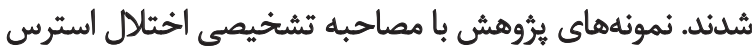

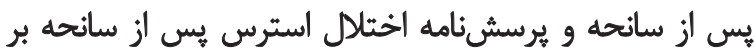

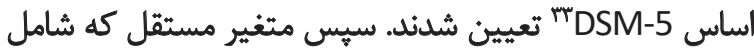

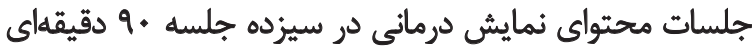

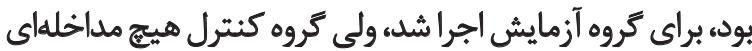

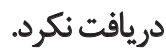

بعد از اتمام جلسات آموزشى، دوباره از دو كروه آزمايشى و

33. Posttraumatic Stress Disorder Checklist for DSM5 (PCL-5)

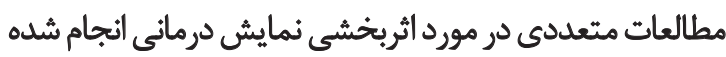

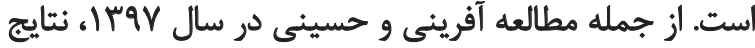
يُروهش آنها نشان داده است، درمان سايكودرام باعث كاند

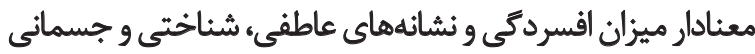

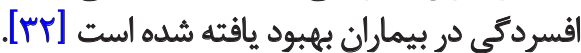
باقرى، سعادت و بولادى به اين نتيجه رسيدند كه سايكودرام

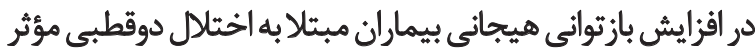

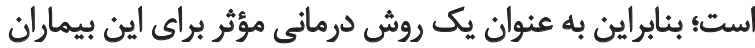

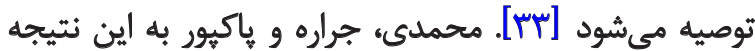

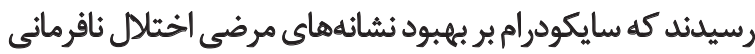
مقابلهجويانه "Wانشآموزان مقطع ابتدايى مؤثر است [MF].

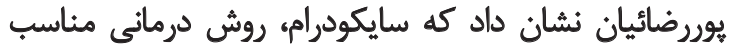

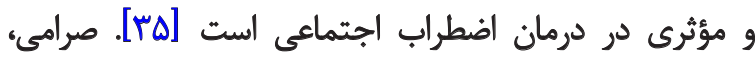

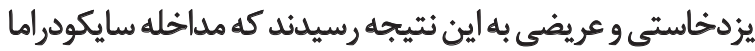

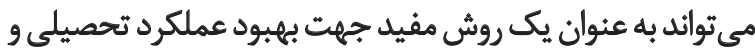

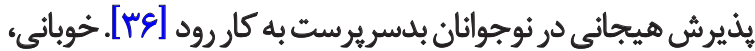

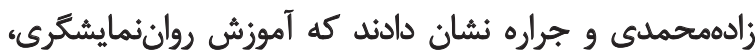

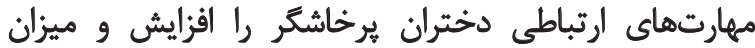

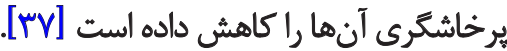

راجرز و كاسوويجز به بررسى سايكودرام؛ مفهوم، تكامل، شواهد

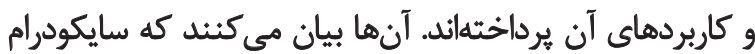

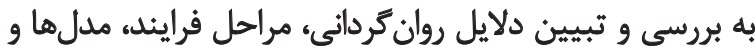

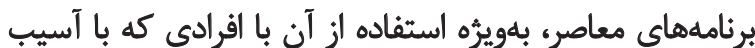

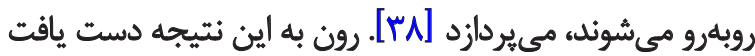

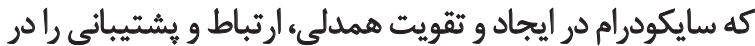

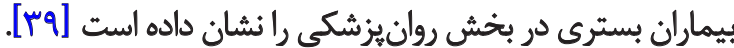

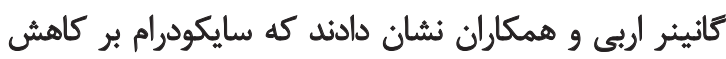

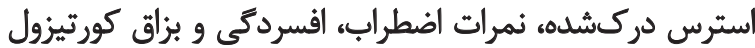

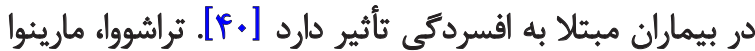

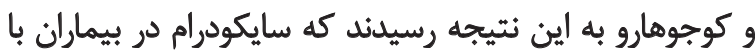

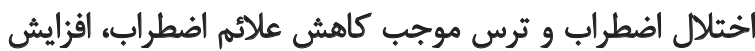

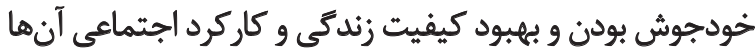

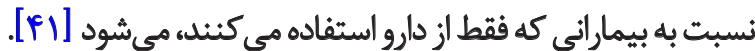

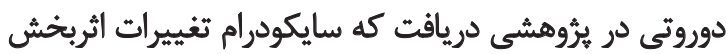

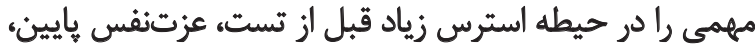

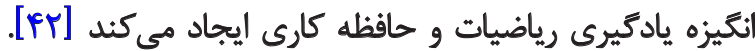

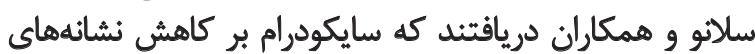

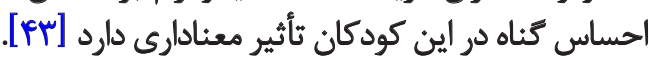
در انتها با توجه به اينكه كودكان و دانشآموزان هر كشورى از سرمايههاى فكرى و معنوى آن كشور هسثند، تأمين سلامت ديث

32. Oppositional Defiant Disorder 
جدول ا. ضريب آلفاي كروئباخ بيرسشنامه PCL-5

\begin{tabular}{|c|c|}
\hline ضريب آلفاى كرونباخ & ملاكهاى تشخيصى هبرسشنامه \\
\hline - /AAT & B ملاك \\
\hline . NG & ملاك C \\
\hline Mme & Dلاك D \\
\hline.$M r$ & ملاك E \\
\hline - MFr & كل يرسش نامه \\
\hline
\end{tabular}

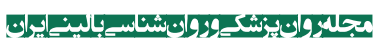

از مصاحبه تشخيصى PTSD بر اساس معيارهاى DSM-5 و

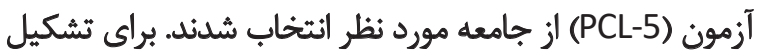

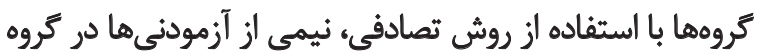

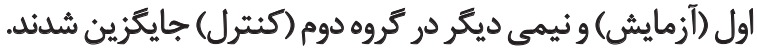

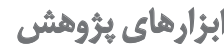

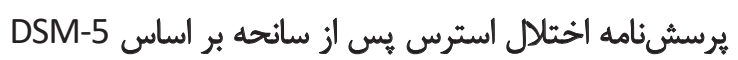

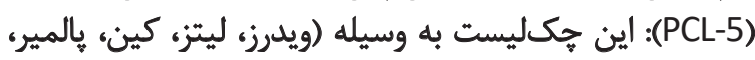

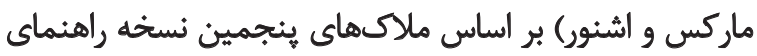

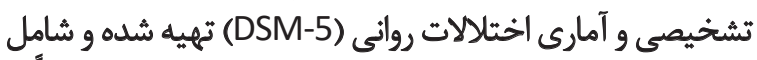

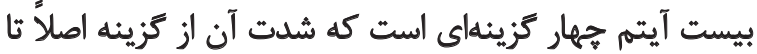

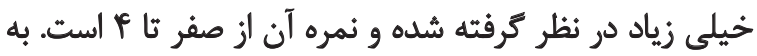

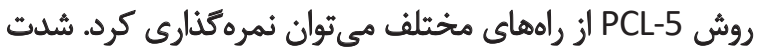

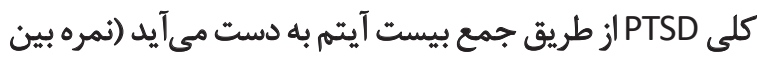

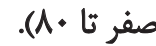

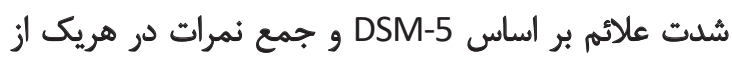

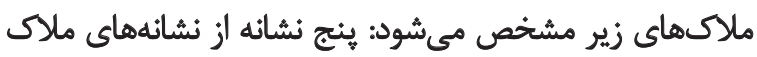

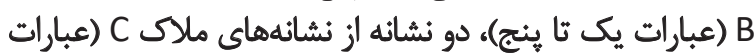

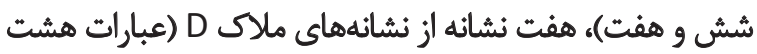

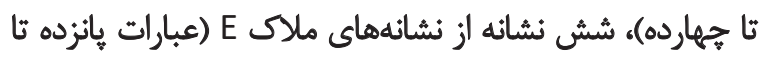

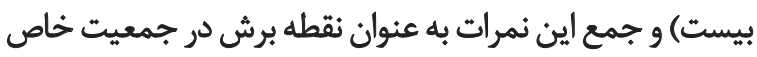

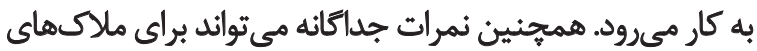

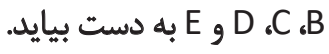

تشخيص موقت PTSD از طريق نمره دو (شدت متوسط و

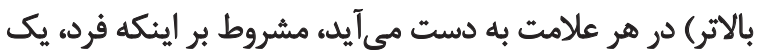

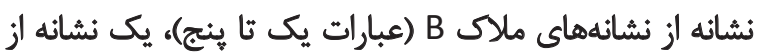

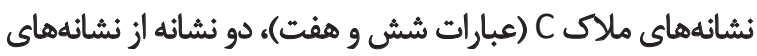

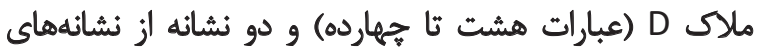

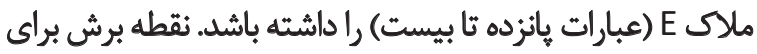

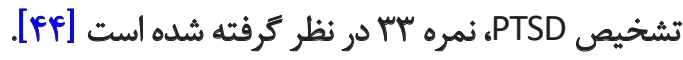

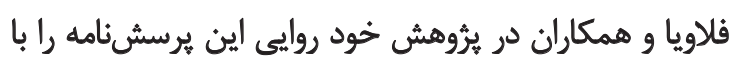

كنترل يس آزمون با همكارى و كمك معلم به عمل آمد. در آخر،

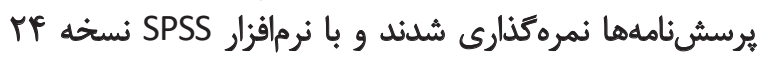

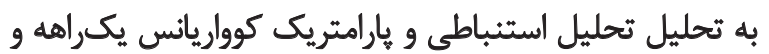

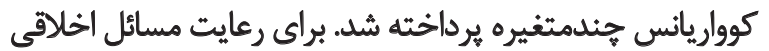

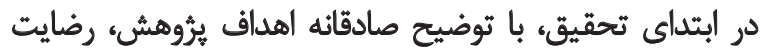

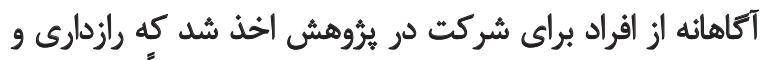

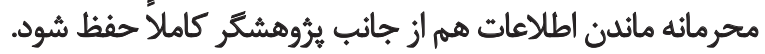

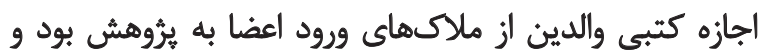

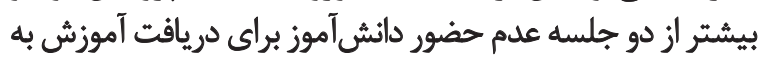

$$
\text { منزله خروج از نمونه است. }
$$

جامعه آمارى يُروهش از بين دانشآموزان يسر داراى اختلال

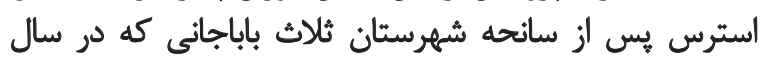

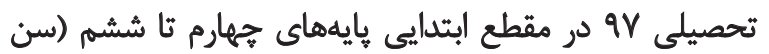

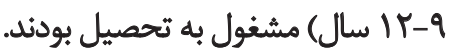

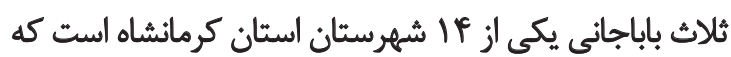

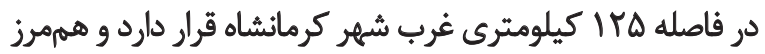

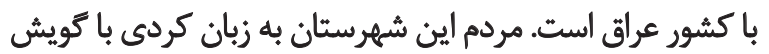

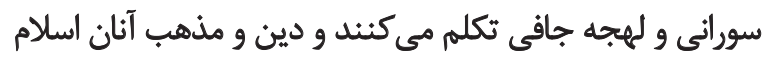
و اهل سنت است.

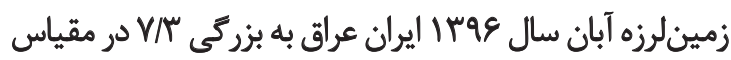

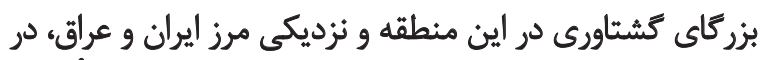

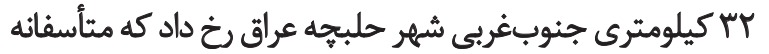

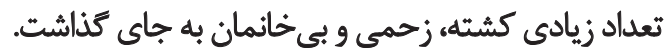
براى انتخاب نمونه ابتدا به اداره آموزش و يرورش شهرئاني

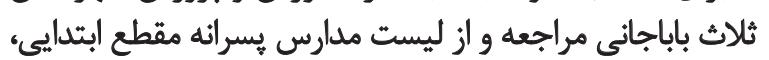

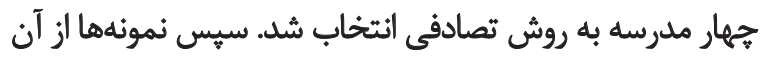
مدارس به صورت هدفمند انتخاب شدند.

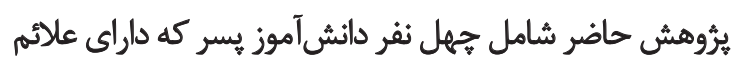

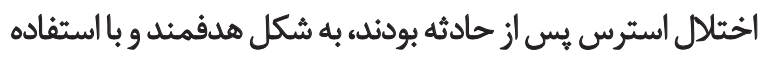


جدول r. خلاصه جلسات آموزشى نمايشدرمائى

\begin{tabular}{|c|c|c|c|}
\hline 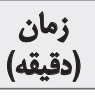 & روش محتوا تكنيك & هدف & جلسات \\
\hline q. & 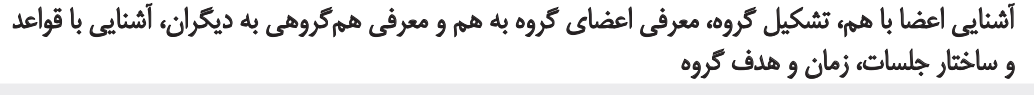 & آنشنايي & 1 \\
\hline q. & صميميت، بازى با توب براى تقويت توجه، دقت و عملكرد حسى حركتى و انجام حركات ريتميك و هماهنى & اعتمادسازى & r \\
\hline q. & 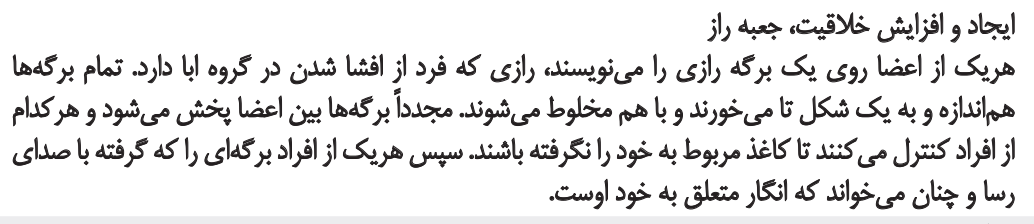 & اعتمادسازى & $r$ \\
\hline q. & 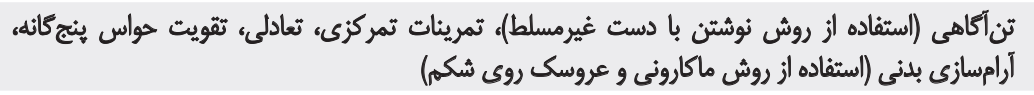 & نشانهشناسي جسمى & r \\
\hline q. & 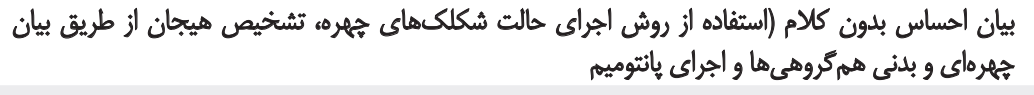 & نشائشأشناسى جسمي / هيجانيى & $\Delta$ \\
\hline 9. & 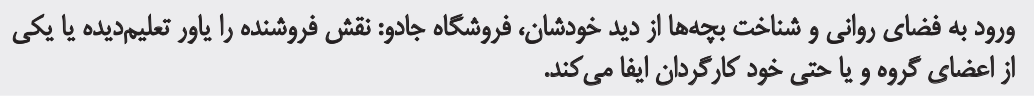 & ارتباط & 8 \\
\hline q. & 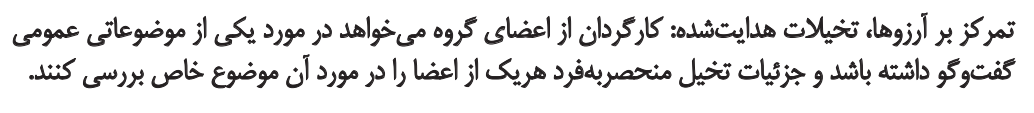 & 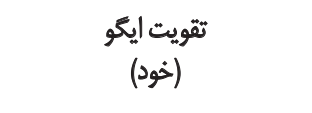 & $v$ \\
\hline १. & 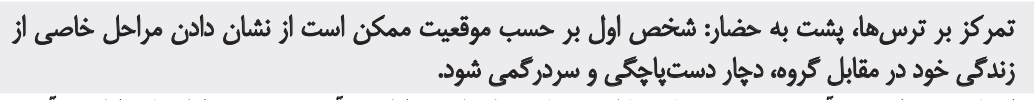 & 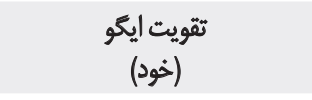 & $\wedge$ \\
\hline q. & 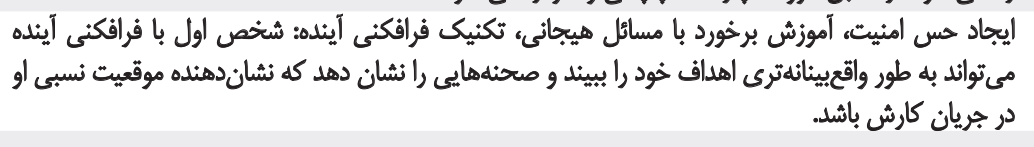 & 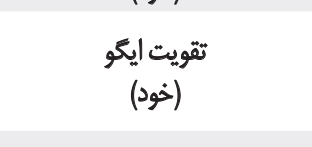 & 9 \\
\hline 9. & 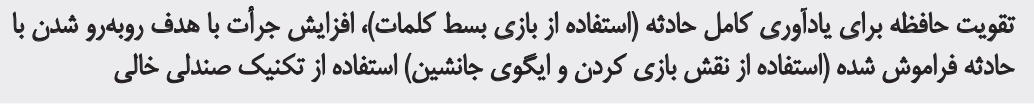 & زميئهسازى براى مواجها & 1. \\
\hline q. & 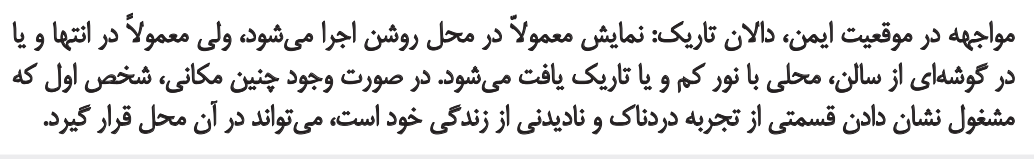 & 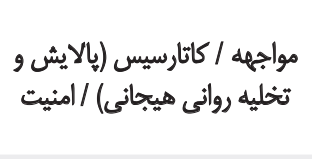 & 11 \\
\hline 9. & 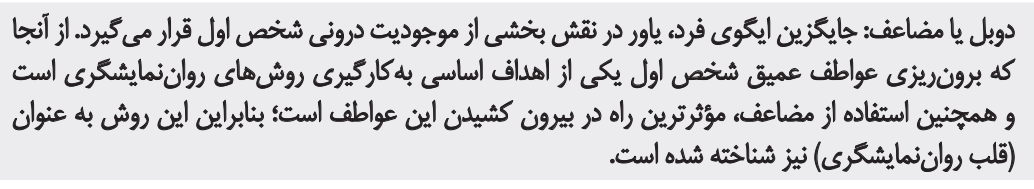 & مواجهه / كاتارسيس / امنيت & ir \\
\hline q. & 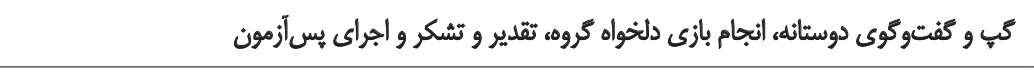 & 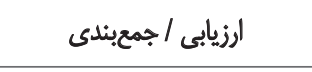 & Ir \\
\hline
\end{tabular}

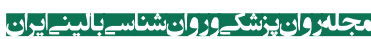

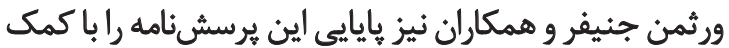

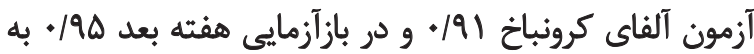

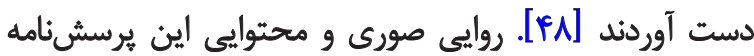

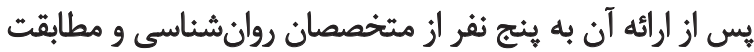

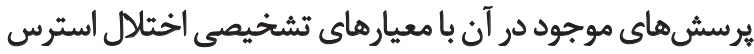

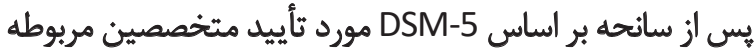

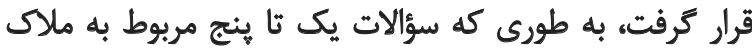

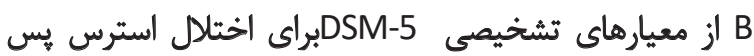

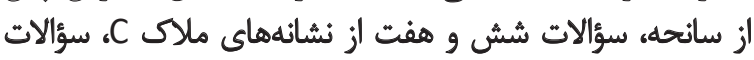

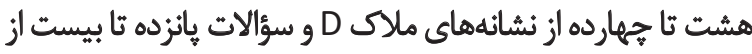

تحليل عامل تأييدى بررسى و ثأييد كردند [Fها ]. هاوكار ابراهيم

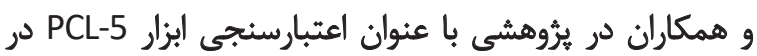

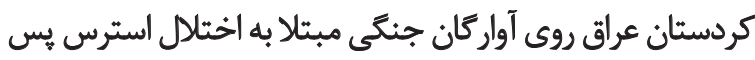

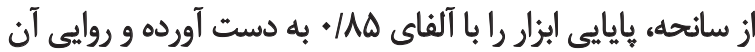

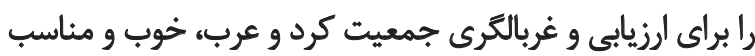

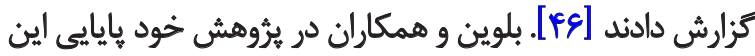

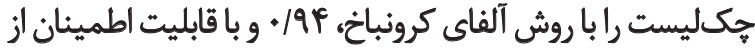

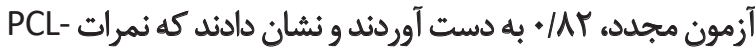

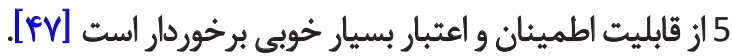


جدول ب. مقايسه نمرات ميانكين و انحراف معيار يرسشنامه استرس يس از سانحه (DSTP) به تفكيك ملاكها در كروه آزمايش و كنترل

\begin{tabular}{|c|c|c|c|c|}
\hline \multicolumn{2}{|c|}{ كروه كثترل } & \multicolumn{2}{|c|}{ كروه آزمايش } & \multirow{2}{*}{ ماكs } \\
\hline مياتكين +|نحر افق معيار & نوع أزمون & مياتكين土|نحراف معيار & نو آزهون & \\
\hline $\mid r / T \Delta \pm r / \cdot V e$ & ييش آزمون & $\mid r / \backslash \Delta \pm T / N$ & ييش آزمون & \multirow{2}{*}{ B $s \times 1$} \\
\hline $\mid Y / N \Delta \pm Y / I F$ & يس أزمهون & $1 \cdot / 1 \cdot \pm$ r/Eq & يسآزمون & \\
\hline $8 / 8 \cdot \pm 1 / \cdot 90$ & ييش آزمهون & $8 / \Delta \cdot \pm 1 / \cdot \Delta)$ & ييش آزمون & \multirow{2}{*}{ Cلاك } \\
\hline$\Delta / A \cdot \pm 1 / \Delta V$ & يسآزمون & $F / f \cdot \pm 1 / f r q$ & هي آزمون & \\
\hline $\mid F / / \Delta \pm \Psi / M I V$ & ييش آزمون & $\mid r / 8 \cdot \pm r / / r 1 \Delta$ & ييشأزمون & \multirow{2}{*}{ D D D D } \\
\hline $\mid r / e \Delta \pm r / m r q$ & يسآزمون & IT/LAET/REA & يس آزمون & \\
\hline $1 f / \Delta \cdot \pm r / 1 \Delta a q$ & ييشآزمون & $\mid r / 4 \cdot \pm r / v a r$ & ييش أزمون & \multirow{2}{*}{ E } \\
\hline$|f / \Lambda \Delta \pm \Psi / 8 \Psi|$ & يسأزمون & $1+/ 9 \cdot \pm r / F i r$ & هسأزمون & \\
\hline$F N \Delta \cdot \pm V / \Delta Q$ & ي يششآزمون & $F \& / \& \Delta \pm \& / q 1 \Delta$ & ييشأزمون & \multirow{2}{*}{ نمره كل } \\
\hline PV/ \pm NTRS & يس آزمون & $\mathrm{rV} / \Delta+ \pm V / A r^{*}$ & يسأزمون & \\
\hline
\end{tabular}

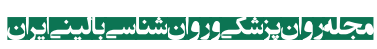

معيار متغير ميزان علائم و تنيدكى هاى استرس ثيس از سانحه

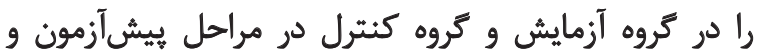
يس آزمون نشان مي دهند.

نتايج جدول شماره ب نشان ميدهد كه ميانكين نمرات كروه

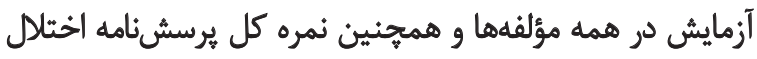

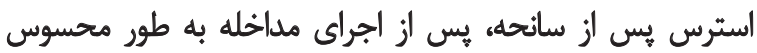

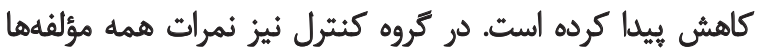

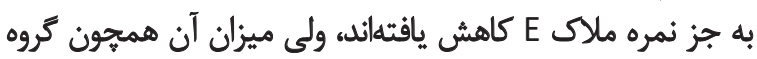

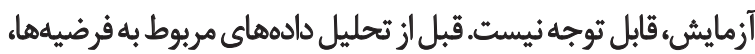

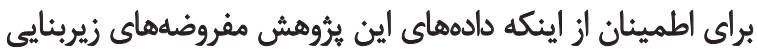

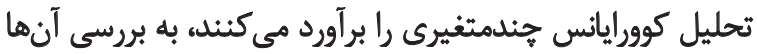

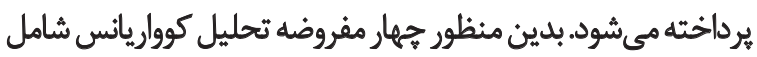

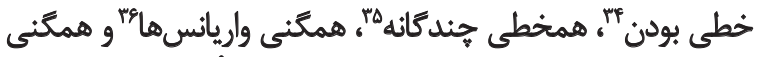

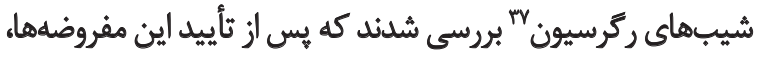

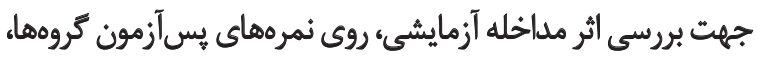

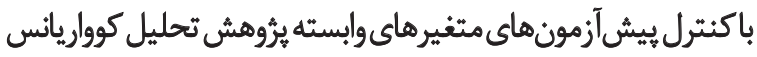

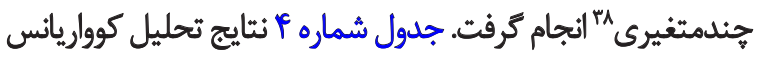

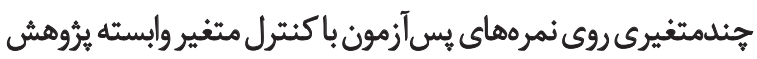
رانشان مي دهد.

34. Linearity

35. Multicollinearity

36. Homogeneity of Variance

37. Homogeneity of Regression

38. MANCOVA
نشانههاى ملاك E براى تشخيص PTSD بودند كه مورد تأييد قرار

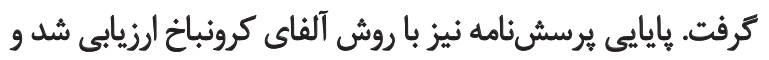

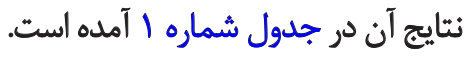

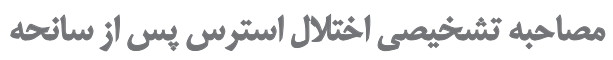

فرم اين مصاحبه بر اساس ملاكىهاى ينجمين نسخه راهنماى

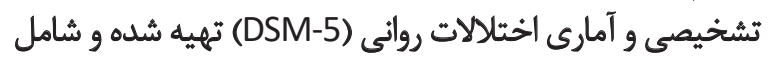
سؤالاتى است كه ملاكهاى PTSD را شامل مىشود و در در اين

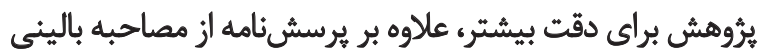

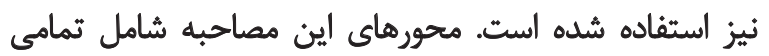

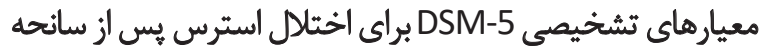

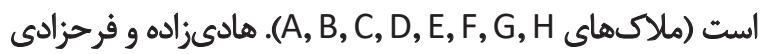
اين مصاحبه را در كتاب خود قيد كردهاند و محور رهاي آن براي في مادي

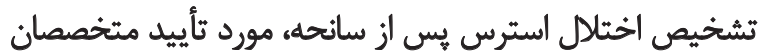

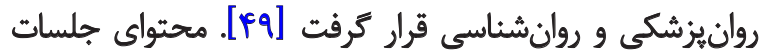
آموزشى در جدول شماره بارائه شده است

ladiot

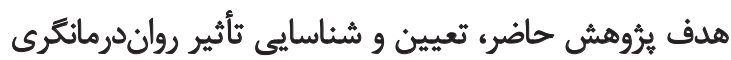

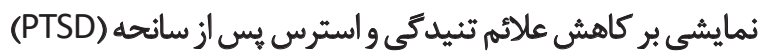

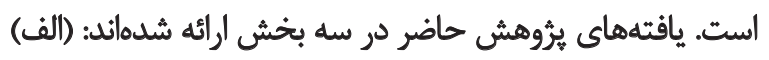

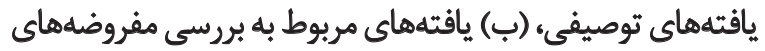

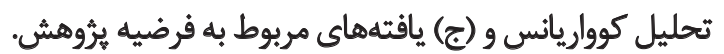
جدول شماره ب ياقتههاي توصيفي شامل ميائكين و انحراف 
جدول F. نتايج تحليل كوواريانس جيندمثغيرى

\begin{tabular}{|c|c|c|c|c|c|c|}
\hline اندازه اثر & سطح معنا دارى & df قرضيه & df خط & ارزش & أزمون & اثر \\
\hline.$/ 01 Y$ &.. .1 & $\Delta$ & r. & . IFT & اثر ييلايى & \multirow{4}{*}{ كروه } \\
\hline.$/ \Delta 1 r$ & $1 / .1$ & $\Delta$ & r* &.$/ r r a$ & لمبداى ويلكز & \\
\hline $.101 T$ & $.1 . .1$ & $\Delta$ & r. & V/geg & اثر هثلينك & \\
\hline.$/ 01 Y$ & $\% 1$ & $\Delta$ & $r *$ & W/afe & بزركترين ريشه روى & \\
\hline
\end{tabular}

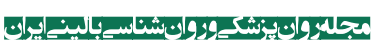

جدول ه. نتايج تحليل كوواريانس يكراهه براى مقايسه يس آزمون

\begin{tabular}{|c|c|c|c|c|c|c|}
\hline الندازه اثر & سطح معنادارى & $\mathbf{F}$ & ميانكين مجذورات & df & مجموع مجذورات & مثغير وابسته \\
\hline .1014 & $.10+1$ & rNWE. & DAT/MgT & 1 & DQT/TRY & علائم تنيدكى و استرس يس ازٔ سانحه \\
\hline
\end{tabular}

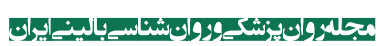

نمايشى بر كاهش علائم اختلال استرس يّس از سانحه انجام

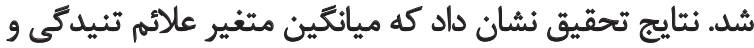

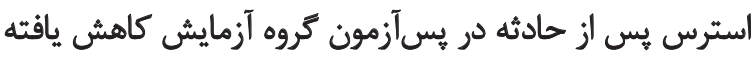

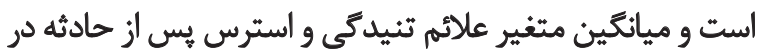

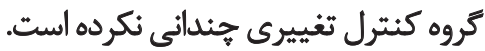

نتايج بررسى فرضيه نشان داد كه تحليل كوواريانس خيندمتغيره

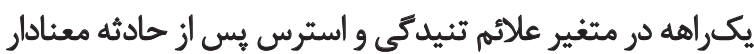

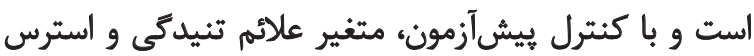

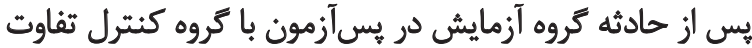
معنادارى دارد. اين يافتهها با برُوهشهاى مشابه همسو است: صادقى و

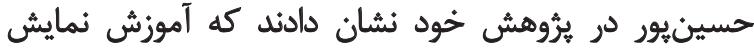

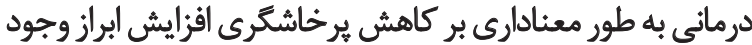

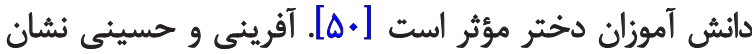

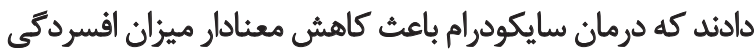

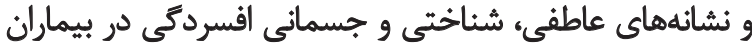

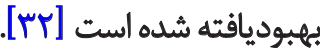

باقرى، سعادت و بولادى به اين نتيجه رسيدند كه سايكودرام در

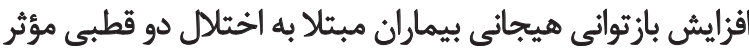

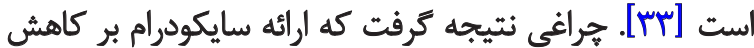

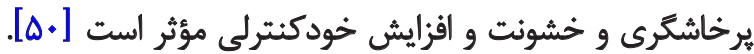

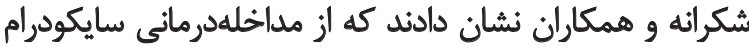

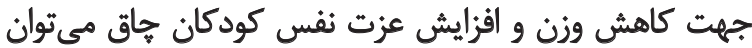

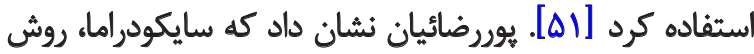

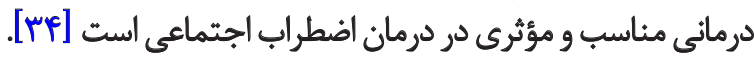

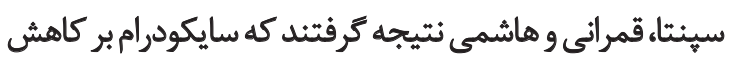

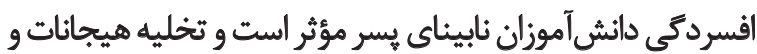

فرضيه كلى رواندرمانكرى نمايشى بر كاهش علائم تنيدكى و

استرس يس از حادثه دانش آموزان ئسر مقطع ابتدايى مؤثر است.

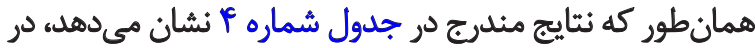

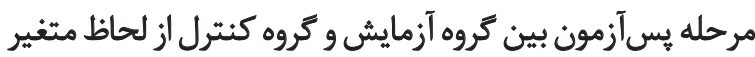

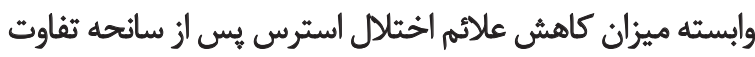

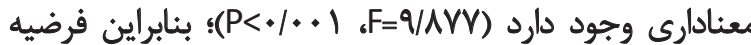

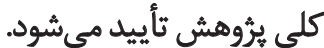

براى بررسى دقيقتر اين اثر، تحليل كواريانس يكراهيه روى نائ

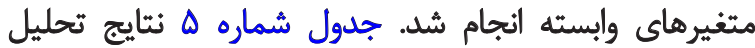

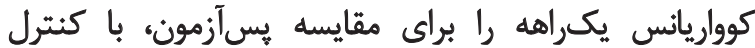
يّيش آزمون هاي متغيرهاي وابسته در كروها آزمايش و وكروه كنترل رانشان مي أنهوند.

همان طور كه نتايج مندرج در جدول شماره ه نشان هي ندهد،

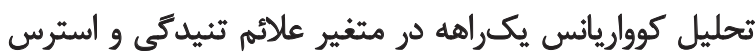

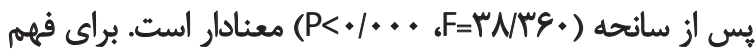

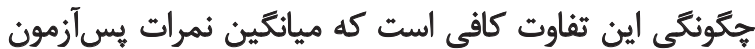

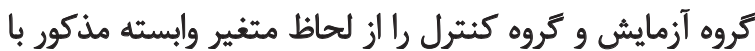

$$
\text { يكديكر مقايسه كنيم. }
$$

با توجه به نتايج مندرج در جدول شماره ؟ا، ميانغين يسآزمون

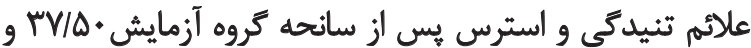

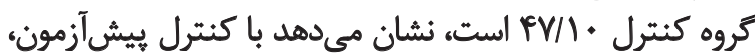

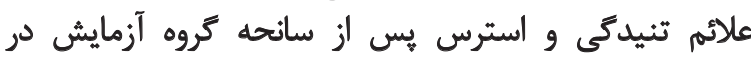

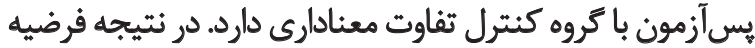

$$
\text { يثروش تأييد مي شئود. }
$$

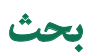

يروهش حاضر با هدف ثعيين و شناسايى ثأثير رواندرمانغرى 
نقش در موقعيتهاى غيرواقعى، مراجعه كنثده مى تواند شيوههاى

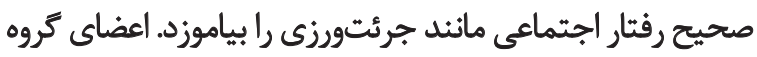

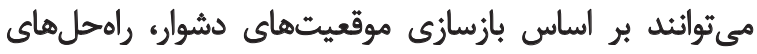

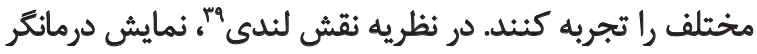

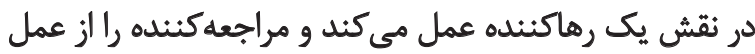

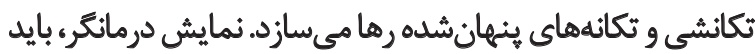

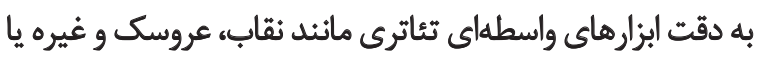

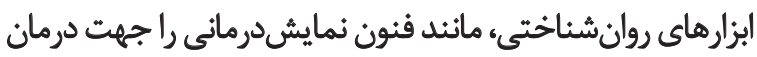

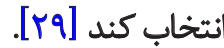

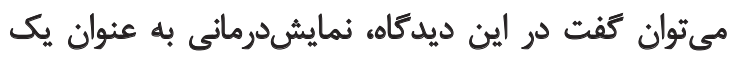

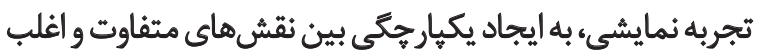

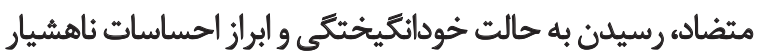

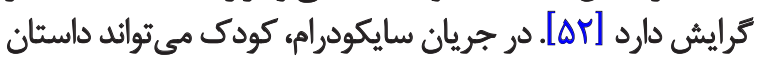

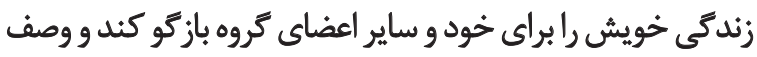

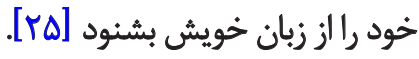

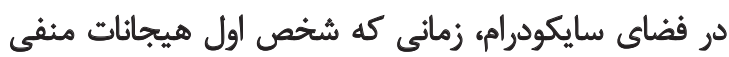

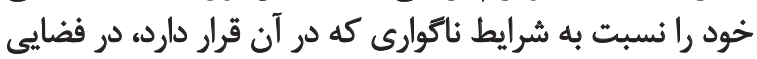

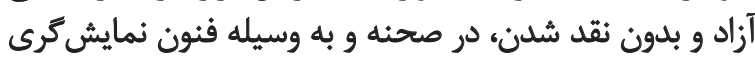

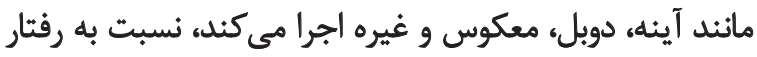

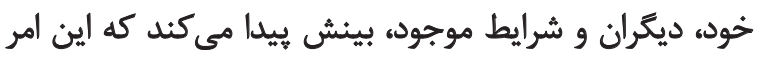

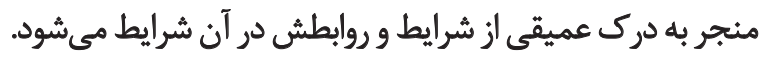

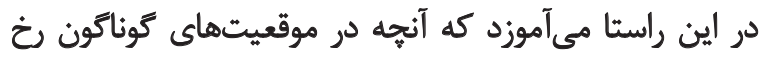
مى دهد، حاصل مجموعهاى از عوامل است [هـهـ]

كودكان در جريان سايكودرام، تجربههاى سخت و آسيبزاي

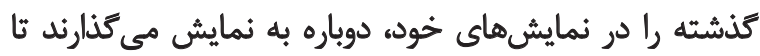

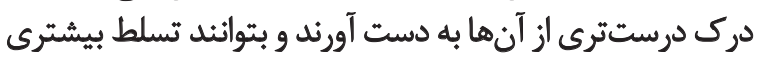

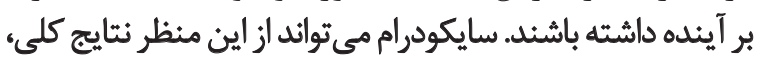

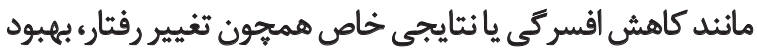

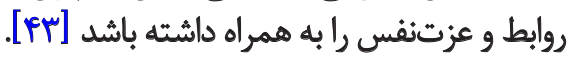

يكى از مههمترين نيازهاى كودكان، تجربه موقعيتهايى است

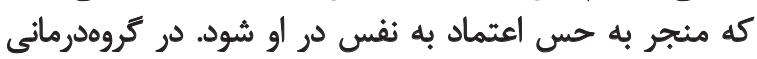

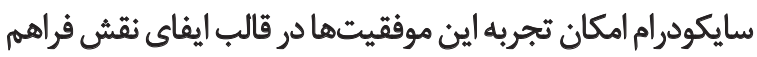

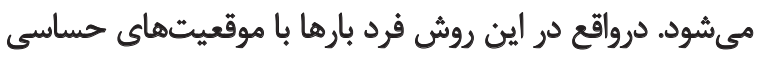

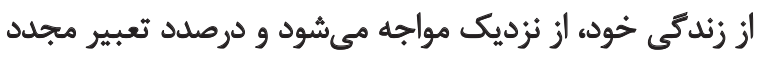

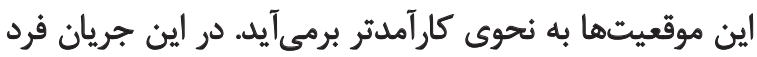

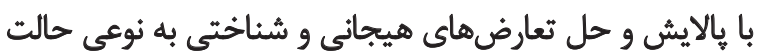

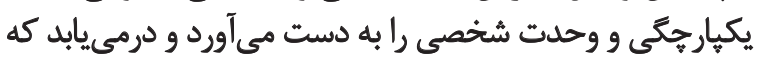

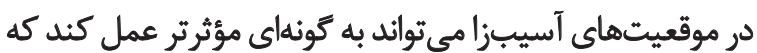

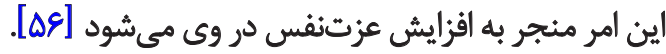
در فضاى امن، افراد مىثوانند بهراحتى دست به خطر بزنند و

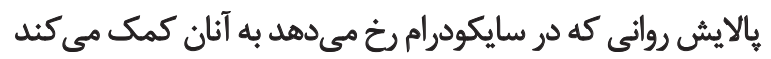

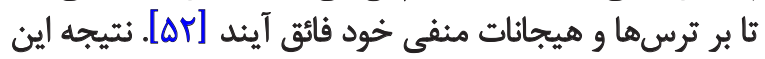

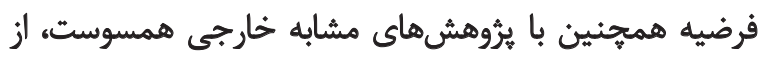

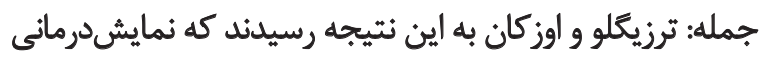

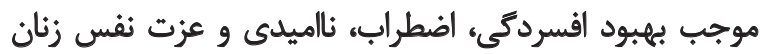

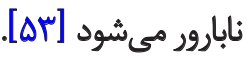

رون به اين نتيجه دست يافت كه سايكودرام در ايجاد و تقويت

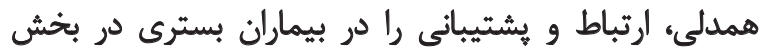

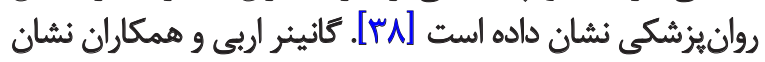

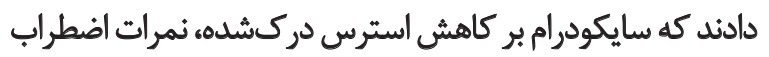

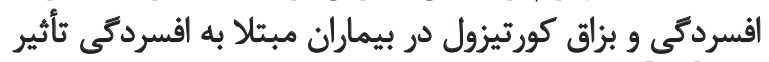

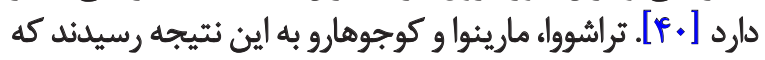

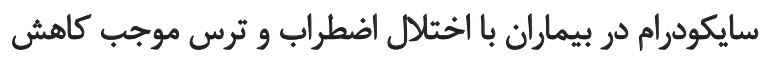

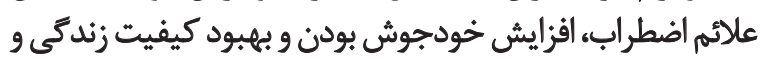

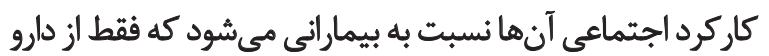

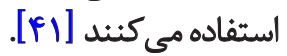
كراتوجويل دريافت كه سايكودرام بر كاهش نشانهائ إنائ احساس

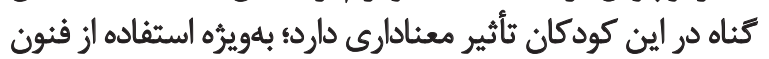

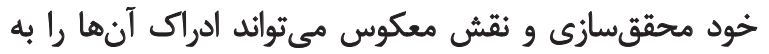

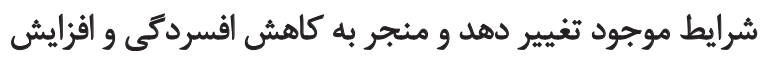

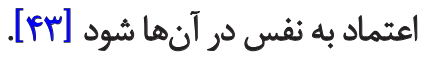

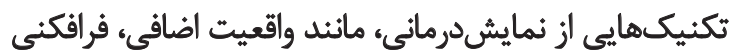

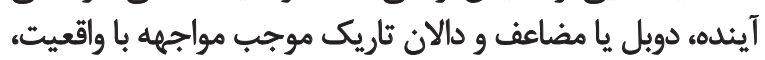

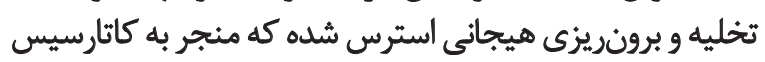

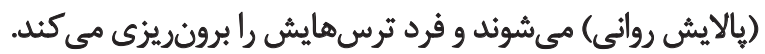

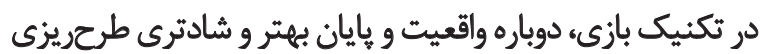

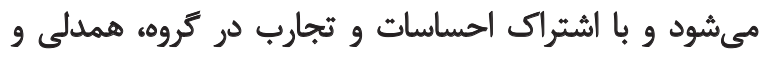
حس مشتركى ايجاد مىشود كه موجب إيجاد احساس امنيت در اعضاى كروه مي شيود.

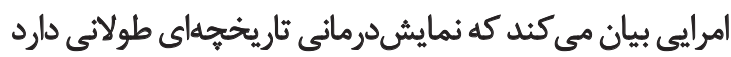

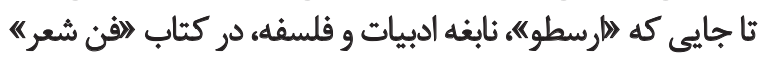

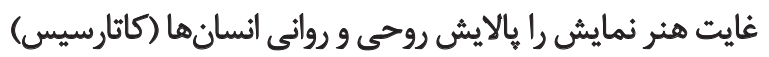

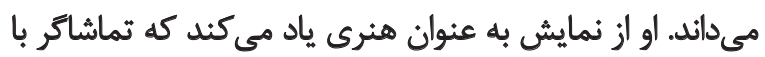

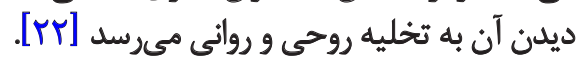
در نمايشدرماني فرد با كشف و به نمايش در در آوردن ابعاد

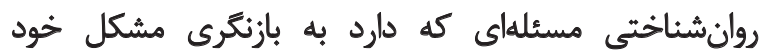

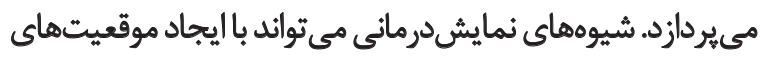

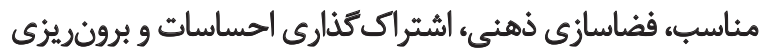
آنها درك بهترى از واقعيت را در فرد ايجاد كرده و از اضطراب و استرس وى بكاهد. يكى ازفنون نمايشدرمانى، ايفاى نقش است. باستفادهاز ايفاى 


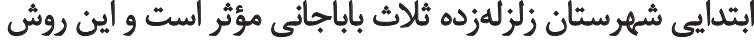

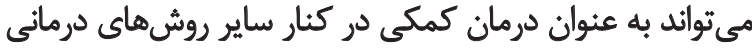

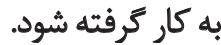

نتايج اين يُروهش مي تواند براى روانشناسان، مربيان تئاتر و

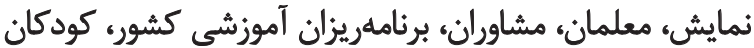

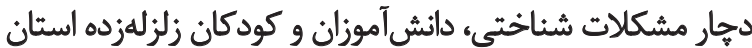

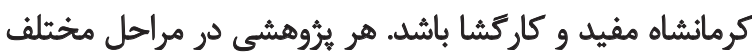

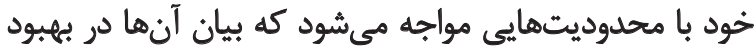
كيفيت يثوهش هاى مشابه در آينده مؤثر خواهد بوديت محدوديت عمده اين يُروهش آن بود كه ابرار بومىسازيشده

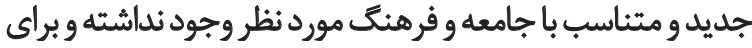

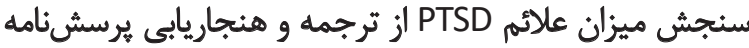

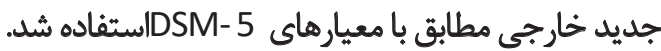
دوره يميكيرى نيز به دليل همين محدوديت؛ يعنى تعطيل

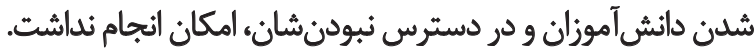

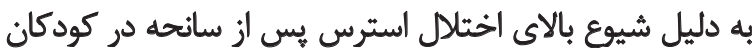

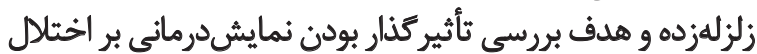

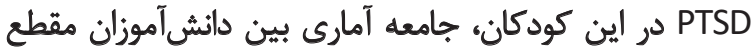

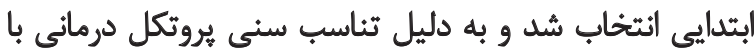

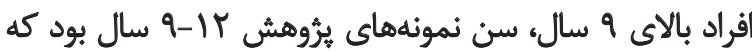

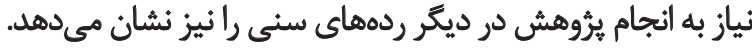

ييشنهاد مىشود تحقيقات مشابه همين يروهش در درئر ديخر

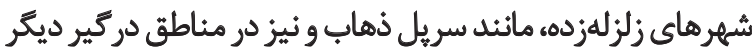

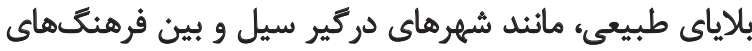

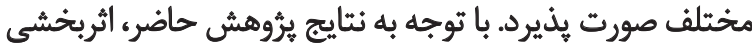

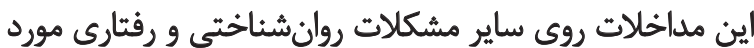

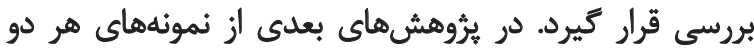

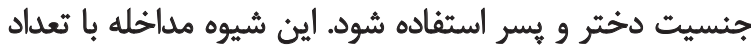

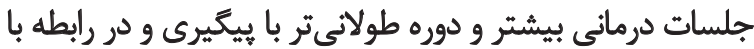
ساير مشكلات كودكان نيز انجام شودان

بيشنهاد مي شود نهادهاى مربوطه به انجام مداخلههاى

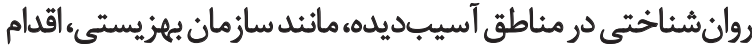

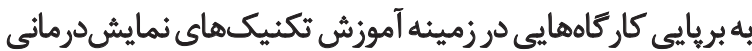

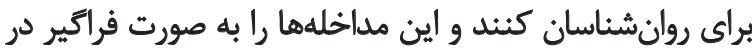
ديكر مناطق دركير با بحران انجام دهند.

مالاحظات اخلاقى

\section{بيروى أز أصول الخلاق يثوهش}

همه اصول اخلاقى در اين مقاله رعايت شده است.

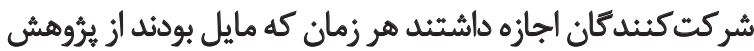

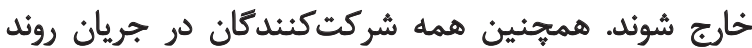

در نتيجه عمل خُود را مشاهده و ارزيابي كنين. سايكودرام نوعى بائي

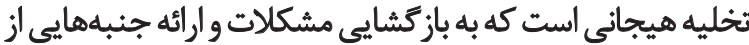

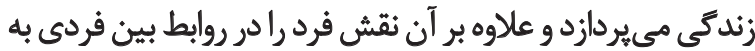

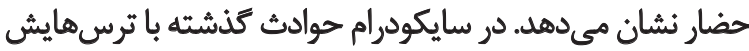

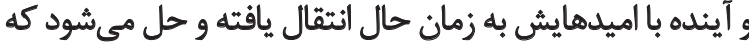

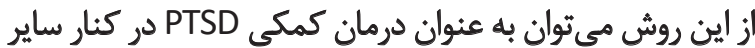

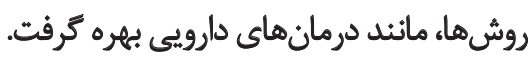

\section{تبيجلكَيرى}

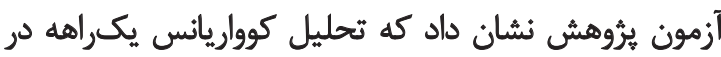

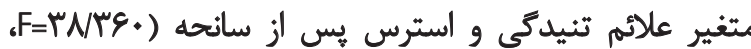

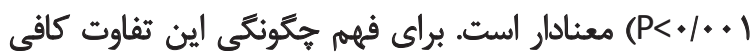

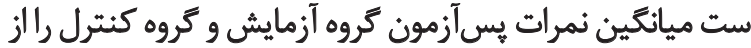
لحاظ متغير وابسته يادشده با يكديكر مقايسه كنيم. با توجه به نتايج مندرج در جدول شماره ب ميانكين يس آزمون

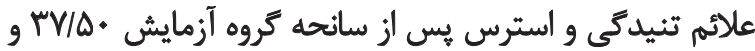

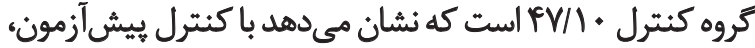

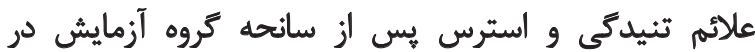

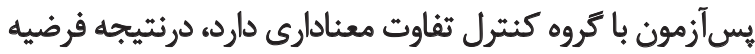
ئروهش تأييد مي شرود.

شواهد متعددى نشان مي دهند كه از جمله عوارض رواثى كه

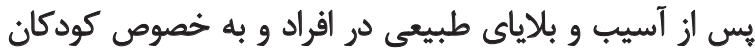

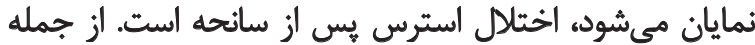

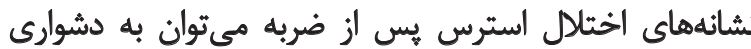

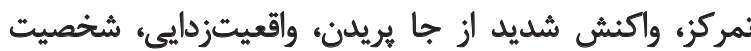

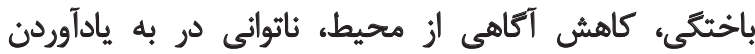

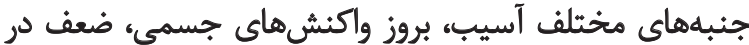

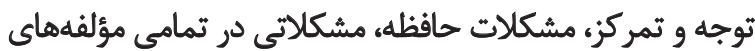

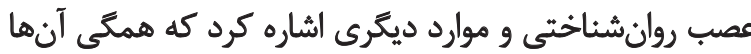
باعث كاهش سلامت عمومى مي شونئد روشهاى مختلف درمانى براي اين اختلال وجود دارد كه

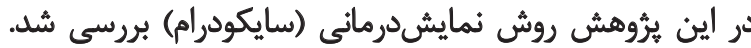

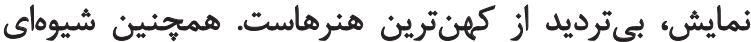

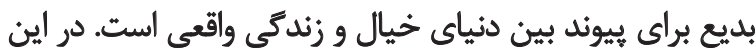

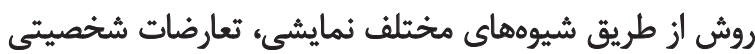

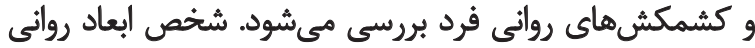

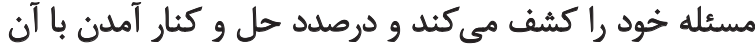

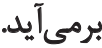

در اين يُروهش تحليل آمارى يافتهها و بررسي نتايج و مطابقت

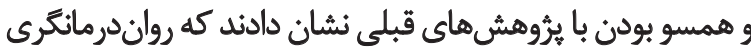

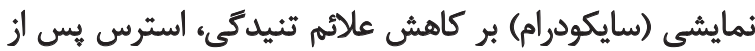

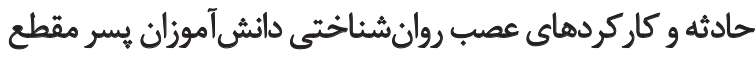




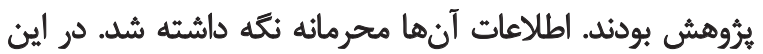

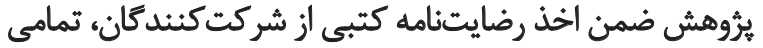

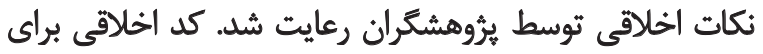

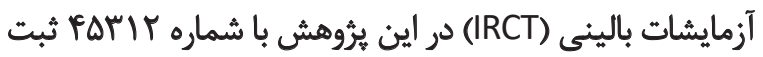
شده است.

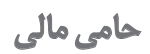
اين يُروهش هيجّونه كمك مالى از سازمانىهاى دولتى، خصوصى و غيرانتفاعى دريافت نكرده است مشاركت ثويسندتًان

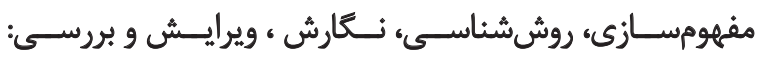

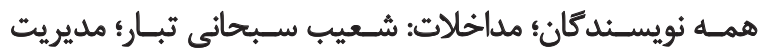

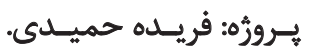

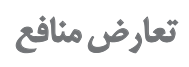

بنابر اظهار نويسنده مسئول، اين مقاله تعارض منافع ندارد.

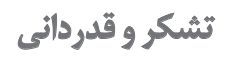

در بايان از مجموعه آموزش و يرورش شهرستان ثلاث باباجانى و مديران مدارس اين شهرستان تشكر و قدردائى مى منيتيم. 


\section{References}

[1] Evazi A, Nourbala A, Maysami A. [Comparison of the prevalence of posttraumatic stress disorder, 18 months after the Bam earthquake in two cities of Bam and Kerman (Persian)]. Journal of Rescue and Relief. 2016; 8(1,2):55-67. http://jorar.ir/article1-254-en.html

[2] Nie C, Yang L, Li H. Macro assessment of seismic population vulnerability in China. Progress in Geography. 2012; 31(3):375-82. https://en.cnki.com.cn/Article_en/CJFDTotal-DLKJ201203013.htm

[3] American Psychiatric Association. Diagnostic and statistical manual of mental disorders. Washington, DC: American Psychiatric Association; 2013. [DOI:10.1176/appi.books.9780890425596]

[4] Yoon S, Kim YK. Neuroendocrinological treatment targets for posttraumatic stress disorder. Progress in Neuro-Psychopharmacology and Biological Psychiatry. 2019; 90:212-22. [DOI:10.1016/j. pnpbp.2018.11.021] [PMID]

[5] Caffo E, Belaise C. Psychological aspects of traumatic injury in childre and adolescents. Child and adolescent Psychiatric Clinics of North America. 2003; 12(3):493-535. [DOI:10.1016/S10564993(03)00004-X]

[6] Kuo HW, Wu SJ, Ma TC, Chiu MC, Chou SY. Posttraumatic symptoms were worst among quake victims with injuries following the Chi-quake in Taiwan. Journal of Psychosomatic Research. 2007; 62(4):495-500. [DOI:10.1016/j.jpsychores.2004.11.012] [PMID]

[7] Lee KS, Joo SY, Seo CH, Park JE, Lee BC. Work-related burn injuries and claims for post traumatic stress disorder in Korea. Burns. 2019; 45(2):461-465. [DOI:10.1016/j.burns.2018.08.016] [PMID]

[8] Yang YF, Liu XX, Zeng ZQ, Xiang YJ, Liu ZY, Hu XQ, et al. A follow-up study on the post-traumatic stress disorders among middle school students in Wenchuan earthquake region. Zhonghua yu Fang yi xue za zhi [Chinese Journal of Preventive Medicine]. 2011; 45(4):354-8. [PMID]

[9] Benjamin J, Sadok VA, Pedro R. Psychiatry Summary; Behavioral Sciences [Rezaei F. Persian trans.]. Tehran: Arjmand Publication; 2018

[10] Darharaj M, Moradi A, Hasani J, Amiri H. [Everyday memory in adolescents with posttraumatic stress disorder before and after treatment: Effectiveness of cognitive behavior therapy (Persian)]. Advances in Cognitive Sciences. 2016; 18(3):56-67. http://icssjournal.ir/article-1-504-en.html

[11] Hornor, G. Posttraumatic stress disorder. Journal of Pediatric Health Care. 2013; 27(3):29-38. https://doi.org/10.1016/j.pedhc.2012.07.020

[12] Bryant RA, Edwards B, Creamer M, O'Donnell M, Forbes D, Felmingham KL, et al. The effect of post-traumatic stress disorder on refugees 'parenting and their children's mental health: A cohort study. Lancet Public Health. 2018; 3:e249-58. [DOI:10.1016/ S2468-2667(18)30051-3

[13] Bomyea J, Lang AJ. Accounting for intrusive thoughts in PTSD: Contributions of cognitive control and deliberate regulation strategies. Journal of Affective Disorder. 2016; 192:184-90. [DOI:10.1016/j.jad.2015.12.021] [PMID] [PMCID]

[14] Aupperle RL, Melrose AJ, Stein MB, Paulus MP. Executive function and PTSD: disengaging from trauma. Neuropharmacology. 2012; 62(2):686-94. [DOI:10.1016/j.neuropharm.2011.02.008] [PMID] [PMCID]
[15] Surcamp JR. Applied logotherapy for the treatment of posttraumatic stress disorder in men and women united states army veterans. In partial fulfillment of the requirements for the degree of honors baccalaureate of science in public health honors scholar. Corvallis: Oregon State University Honors College. 2015.

[16] Yule W, Smith P, Perrin S. Cognitive Behaviour Therapy for Children and Families. In: Graham PJ, editors. Cognitive behavior therapy for children and families. New York: Cambridge University Press; 2005. [DOI:10.1017/CBO9780511543845.020]

[17] Vahida F, Soltaninejad A, Soltaninejad A. Sociological analysis of Bam earthquake. Sociological Studies of Iran. 2013; 2(7):9-23.

[18] Asl Mohammad Alizadeh M, Sadralashrafi M, Pourali M, Ishaqi Sardrood SH. Apples and post-earthquake psychological interventions analysis of post-traumatic research. Paper presented at: National Conference on Pathology and Planning of the effects of the August 12 earthquake in East Azerbaijan Province. 31 December- 1 January; Tabriz, Iran, 2013. https:/ / civilica.com/ doc/230430/

[19] Schuitevoerder S, Rosen JW, Twamley EW, Ayers CR, Sones $\mathrm{H}$, Lohr JB, et al. A meta-analysis of cognitive functioning in older adults with PTSD. Journal of Anxiety Disorders. 2013; 27(6):550-8 [DOI:10.1016/j.janxdis.2013.01.001] [PMID]

[20] Henigsberg N, Kalember P, Petrović ZK, Secic A. Neuroimaging research in posttraumatic stress disorder - Focus on amygdala, hippocampus and prefrontal cortex. Progress in Neuro Psychopharmacology and Biological Psychiatry. 2019; 90:37-42. [DOI:10.1016/j.pnpbp.2018.11.003] [PMID]

[21] Reddemann L, Piedfort-Marin O. Stabilization in the treatmen of complex post-traumatic stress disorders: Concepts and principles. European Journal of Trauma \& Dissociation. 2017; 1(1):11-7 [DOI:10.1016/j.ejtd.2017.01.009]

[22] Amrayi M . Ten Steps to showcase therapy/display therapy in quitting hypnotic habits. Tehran: Tahora Publications. 2014.

[23] Morstad MD. Drama's role in school counseling [MA. thesis]. London: University of Wisconsin-stout. 2003.

[24] Blaner A. Introjection: Psychotherapy by Dramatic Methods; Theatrical Therapy. [H. Haqqshenas, H. Ashkani, Persian trans.] Tehran: Roshd Publications. 2015.

[25] Somov PG. A psychodrama group for substance use relapse prevention training. The Arts in Psychotherapy. 2008; 35(2):151-61. [DOI:10.1016/j.aip.2007.11.002]

[26] Suto H, Maeda J. A self psychological therapy tool based on psychodrama methodology. SICE Journal of Control, Measurement and System Integration. 2018;11(1):26-31. [DOI:10.9746/jcmsi.11.26]

[27] Gatta M, Andrea S, Paolo TC, Giovanni C, Rosaria S, Carolina B, et al. Analytical psychodrama with adolescents suffering from psycho-behavioral disorder: Short-term effects on psychiatric symptoms. The Arts in Psychotherapy. 2010; 37(3):240-7. [DOI:10.1016/j.aip.2010.04.010]

[28] Orkibi H, Feniger-Schaal R. Integrative systematic review of psychodrama psychotherapy research: Trends and methodological implications. PLoS One. 2019; 14(2):e0212575. [DOI:10.1371/ journal.pone.0212575] [PMID] [PMCID]

[29] Kamali N . [Introduction to psychodrama (Persian)]. Tehran Rayagostar Publishing.2018. 
[30] Snow S. Ritual/theatre/therapy. In: Lewis P, Jahnson D, editors. Current approaches in drama therapy. Springfield: Chales C Thomas; 2000.

[31] Navabi Nejad S. [Theories of group counseling and psychotherapy (Persian)]. Qom: Yaran; 2012.

[32] Afarini Y, Hussein E. [The effect of psychodrama on the treatment of depression in patients with improved drug abuse (Persian)]. Knowledge Horizon. 2018; 24(2):96-102. http://hms.gmu. ac.ir/article-1-2883-en.html

[33] Bagheri M, Saadat F, Poladi F. [The effect of psychodram on emotional rehabilitation of patients with type I Bipolar Disorder (Persian)]. Journal of Behavioral Sciences Research. 2018; 16(2):175-81. http://rbs.mui.ac.ir/article-1-597-en.html

[34] Pourrezaian M. [Clinical evaluation of the effect of psychodrama on the treatment of social anxiety: Case study (Persian)]. Journal of Clinical Psychology Studies. 2016; 6(24):29-46. [DOI: 10.22054/JCPS.2016.6513]

[35] Sarrami N, Yazdkhasti F, Oreyzi-Samani HR. [The effectiveness of psychodrama with transactional analysis content on emotion regulation and social-adaptive functions in female adolescent with bad parenting (Persian)]. 2018; 9(4):83-94. https:/ /jcp.semnan.ac.ir/ article_2927_3fd0f83190e75b02ae320b6b8d9efb25.pdf?lang=en

[36] Khubani M, Zadeh Mohammadi A, Gerare J. [The effectiveness of psychodrama on communication and aggression skills in aggressive girls (Persian)]. Journal of Applied Psychology. 2013; 7(4):27-44. https://www.sid.ir/en/journal/ViewPaper. aspx?id=387889

[37] Rogers CA, Kosowicz D. Psychodrama: Conception, evolution, evidence and applications. Australian Counselling Research Journal. 2019; 13(1):30-5. http://www.acrjournal.com.au/resources/ assets/journals/Volume-13-Issue-1-2019/Manuscript6\%20-\%20 Evolution\%20of\%20Psychodrama.pdf

[38] Ron Y. Psychodrama's role in alleviating acute distress: A case study of an open therapy group in a psychiatric inpatient ward. Frontiers in Psychology. 2018; 9:2075. [DOI:10.3389/fpsyg.2018.02075] [PMID] [PMCID]

[39] Erbay LG, Reyhani I, Unal S, Ozcan C, Ozgoçer T, Uçar C, et al. Does psychodrama affect perceived stress, anxiety-depression scores and saliva cortisol in patients with depression. Psychodrama and Saliva Cortisol. 2018; 5(10):970-5. [DOI:10.30773/ pi.2018.08.11.2] [PMID] [PMCID]

[40] Tarashoeva G, Marinova-Djambazova P, Kojuharov H. Effectiveness of psychodrama therapy in patients with panic disorders - final results. International Journal of Psychotherapy. 2017; 21(2):55-66. http://www.fepto.com/wp-content/uploads/Effectiveness_of_Psychodrama_Therapy_in_Patients_w.pdf

[41] Dorothea G. Effectiveness of psychodrama group therapy on pupils with mathematics anxiety. Z Psychodrama Soziometr. 2016; 15:197-215. [DOI:10.1007/s11620-015-0299-4]

[42] Celano CM, Beale EE, Mastromauro CA, Stewart JG, Millstein RA, Auerbach RP, Bedoya CA, et al. Psychological interventions to reduce suicidality in high risk patients with major depression: A randomized controlled trial. Psychological Medicine. 2017; 47(5):810-21. [DOI:10.1017/S0033291716002798] [PMID] [PMCID]

[43] American Psychiatric Association. The diagnostic and statistical manual of mental disorders. Philadelphia: American Psychiatric Association; 2013.
[44] Osorio FL, Silva Thiago DA, Santos Rafael GD, Chagas Marcos HN, Chagas Natalia MS, Sanches RF et al . Posttraumatic Stress Disorder Checklist for DSM-5 (PCL-5): transcultural adaptation of the Brazilian version. Archives of Clinical Psychiatry. 2017; 44(1):10-19.[DOI:10.1590/0101-60830000000107]

[45] Hawkar I, Verena E, Claudia C, Azad AI, Frank N. The Validity of Posttraumatic Stress Disorder Checklist for DSM-5 (PCL-5) as Screening instrument with Kurdish and Arab displaced populations living in the Kurdish region of iraq. BMC Psychiatry. 2018; 18:259. [DOI:10.1186/s12888-018-1839-z] [PMID] [PMCID]

[46] Ibrahim H, Ertl V, Catani C, Ismail AA, Neuner F. The validity of Posttraumatic Stress Disorder Checklist for DSM-5 (PCL-5) as screening instrument with Kurdish and Arab displaced populations living in the Kurdistan region of Iraq. BMC Psychiatry. 2018; 18:259. [DOI:10.1186/s12888-018-1839-z] [PMID] [PMCID]

[47] Wortmann, JH, Alexander HJ, Weathers FW, Resick PA, Dondanville KA, Hall-Clark, B, et al. Psychometric analysis of the PTSD Checklist-5 (PCL-5) among treatment-Seeking military Service members. Psychological Assessment. 2016; 28(11):1392-403. [DOI:10.1037/pas0000260] [PMID]

[48] Hadi Zadeh MH, Farzadi N. [Practical Guide to the DSM_5 Psychiatric Disorders Interview (Persian)]. Tehran: Savalan; 2018.

[49] Sadeghi A, Hosseinpour M. Evaluation of the effectiveness of psychodrama theater therapy on reducing aggression and increasing the expression of female high school students in Izeh in the academic year of 1996-97. Paper presented at: Second International Conference on Psychology, Consultation, Education. 22 November 2018; Mashhad, Iran. https://en.civilica.com/1/9595/

[50] Cheraghi M. Determining the effectiveness of psychodrama on reducing aggression and violence and increasing self-contro of young people in Abdanan in 2016. Paper presented at: Fourth World Conference and First National Conference on Modern Research in Iran and the World in: Psychology, Educational Sciences, Law, Social Sciences. 18 May 2019; Shiraz, Iran. https://search. ricest.ac.ir/inventory/36/92317.htm

[51] Shokraneh A, Neshat Dost H, Abedi M, Talebi H. [The effect of psychodrama on body mass index, self-esteem and cognitiveemotion regulation in obese female children (Persian)]. Journal of Behavioral Sciences Research. 2016; 14(3):331-8. http://rbs.mui. ac.ir/article-1-484-en.html

[52] Sepanta M, Qamrani A, Hashimi M. The effect of psychodrama on role-playing method on reducing depression in blind male students. Third National Conference on Psychology and Behavioral Sciences, Tehran: Narkish Information Institute. 2015.

[53] Terzioglu C, Ozkan B. Psychodrama and the Emotional State of Women Dealing with Infertility. Sexuality and Disability. 2018 36(3):87-99. [DOI:10.1007/s11195-017-9514-8]

[54] Landy RJ, Mclellan L, Mcmullian S. The educational of the drama therapists: In search of guide. Journal of the Arts in Psychotherapy. 2005; 32(4):272-92. [DOI:10.1016/j.aip.2005.02.005]

[55] Hinshelwood RD. The early experimenters with groups. Journal of Group Analysis, 2004; 37:323-33. [DOI:10.1177/533316404042850]

[56] Ahmadi Froushani SH, Yazdkhasti F, Arizi HR. [The effect of psychodrama with spiritual content on students' happiness, enjoyment and mental health (Persian)]. Journal of Applied Psychology. 2013; 2(26):7-23. https://apsy.sbu.ac.ir/article_95924.html 